\title{
Phenolic compounds and antioxidant activity of Macedonian red wines
}

\author{
Violeta Ivanova-Petropulos ${ }^{\mathrm{a}, *}$, Isidro Hermosín-Gutiérrez ${ }^{\mathrm{b}}$, Borbála Boros ${ }^{\mathrm{c}}$, \\ Marina Stefova ${ }^{\mathrm{d}}$, Trajče Stafilov ${ }^{\mathrm{d}}$, Borimir Vojnoski ${ }^{\mathrm{e}}$, Ágnes Dörnyei ${ }^{\mathrm{c}, \mathrm{f}}$, Ferenc Kilár $^{\mathrm{c}, \mathrm{f}}$ \\ a Faculty of Agriculture, University “Goce Delčev”, Krste Misirkov bb, 2000 Štip, Republic of Macedonia \\ ${ }^{\mathrm{b}}$ Instituto Regional de Investigación Científica Aplicada (IRICA), Escuela de Ingenieros Agrónomos, Universidad de Castilla-La Mancha, Ronda de Calatrava 7. \\ 13071 Ciudad Real, Spain \\ ${ }^{\mathrm{c}}$ Department of Analytical and Environmental Chemistry, Faculty of Sciences, University of Pécs, Ifjúság útja 6., 7624 Pécs, Hungary \\ ${ }^{\mathrm{d}}$ Institute of Chemistry, Faculty of Natural Sciences and Mathematics, Ss. Cyril and Methodius University, Arhimedova 5, 1000 Skopje, Republic of Macedonia \\ ${ }^{\mathrm{e}}$ Department of Enology, Institute of Agriculture, Ss. Cyril and Methodius University, Blvd Aleksandar Makedonski bb, 1000 Skopje, Republic of Macedonia \\ ${ }^{\mathrm{f}}$ Institute of Bioanalysis, Faculty of Medicine,University of Pécs, Szigeti út 12., 7624 Pécs, Hungary
}

\section{A R T I C L E I N F O}

\section{Article history:}

Received 27 April 2013

Received in revised form 9 January 2015

Accepted 20 January 2015

Available online 16 February 2015

\section{Keywords:}

Food analysis

Food composition

Red wine

Vranec

Phenolic compounds

Anthocyanins

Pigments

Antioxidant activity

HPLC-DAD-ESI-MS

\begin{abstract}
A B S T R A C T
The quantitative composition of phenolic compounds and antioxidant activity of Vranec, Merlot and Cabernet Sauvignon wines produced in 2006, 2007 and 2008 were determined and compared. The phenolic profile was established using high-performance liquid chromatography coupled with diode array detector and on line mass spectrometry (HPLC-DAD-ESI-MS and MS/MS) technique. A total of 65 phenolic compounds were determined in the wines including 14 anthocyanins, 18 pyranoanthocyanins, 16 flavonols, 8 hydroxycinnamic acids and their derivatives, 4 stilbenes, gallic acid and 4 flavan-3-ols. Hydroxyphenyl-pyranoanthocyanin content is reported for the first time in Macedonian red wines, ranging between 1.09 and $10.4 \mathrm{mg} / \mathrm{L}$. 10-Carboxy-pyranomalvidin-3-glucoside and 10-p-hydroxyphenyl-pyranomalvidin-3-glucoside were the main compounds from vitisin-like and hydroxyphenyl-like pyranoanthocyanins, respectively. Vranec wines produced in 2008 presented highest concentration of anthocyanins (508 mg/L), vitisins ( $53.1 \mathrm{mg} / \mathrm{L})$, hydroxyphenyl-pyranoanthocyanins (7.35 mg/L), flavonols $(120 \mathrm{mg} / \mathrm{L})$, hydroxycinnamic acid derivatives $(352 \mathrm{mg} / \mathrm{L})$, flavan-3-ols $(98.9 \mathrm{mg} / \mathrm{L})$, stilbenes $(43.9 \mathrm{mg} / \mathrm{L})$ and antioxidant activity $(12.5 \mathrm{mM} / \mathrm{L} \mathrm{TE})$. Cabernet Sauvignon and Merlot had highest flavonols (152 and $119 \mathrm{mg} / \mathrm{L}$ ) and flavan-3-ols concentration (150 and $111 \mathrm{mg} / \mathrm{L}$ ) in 2006 and 2007 , respectively, indicating the important role of variety, climate, storage conditions and winemaking techniques in wine phenolic composition. Factor analysis showed classification of wines according to the variety and content of the phenolic families and color characteristics.
\end{abstract}

(c) 2015 Elsevier Inc. All rights reserved.

\section{Introduction}

Wine contains a number of polyphenolic constituents which determine important sensorial characteristics, such as color, mouthfeel, astringency and bitterness. They are the main components responsible for the differences between red and white wines, especially for the color, taste, and mouth-feel sensations of red wines. Phenolic compounds are classified as flavonoids, including:

\footnotetext{
* Corresponding author at: University “Goce Delčev”, Faculty of Agriculture, Krste Misirkov bb, 2000 Štip, Republic of Macedonia. Tel.: +389 32550 639; fax: +38932390 700 .

E-mail address: violeta.ivanova@ugd.edu.mk (V. Ivanova-Petropulos).
}

anthocyanins; flavan-3-ols, flavonols and dihydroflavonols, and non-flavonoids: hydroxybenzoic acids and derivatives, hydroxycinnamic acids and derivatives, and stilbenes. Anthocyanins are the main pigments in red wines, responsible for the color. The main anthocyanins in wines from Vitis vinifera grape varieties are 3-Oglucosides, 3-O-acetylglucosides, 3-O-p-coumaroylglucosides, and, in a lesser extent, 3-O-caffeoylglucosides of delphinidin, cyanidin, petunidin, peonidin and malvidin (Wulf and Nagel, 1978; Ivanova et al., 2011a).

Flavan-3-ols are the other important group of wine phenolics that could be present as monomers giving the bitter character, and oligomers and polymers contributing to wine astringency (Sarni-Manchado et al., 1999). Furthermore, grapes and red wine are the major dietary sources of stilbenes, considered as 
phytoalexins whose formation in grapes is correlated to disease resistance (Langcake and Pryce, 1976; Langcake, 1981). Moreover, phenolic compounds, such as anthocyanins in red wines, contribute to the antioxidant properties of wines and determine their potential health effect (Rivero-Perez et al., 2008), exhibit a free radical scavenging activity as well as a protective activity against arteriosclerosis, coronary heart disease (Pace-Asciak et al., 1995; Burns et al., 2000) or inhibit the cancer cell growth, as shown in "in vitro" studies (Zhang et al., 2005). The concentration of phenolic compounds in wine depends on the variety, climate, soil, as well as on the oenological practices applied for winemaking and aging and storage conditions (Kelebek et al., 2007; Koyama et al., 2007; Ivanova et al., 2009, 2011a, 2011e; GilMuñoz et al., 2009; Kostadinović et al., 2012). Thus, during the winemaking process, the anthocyanins reach a maximum level after few days of maceration, followed by decrease of the content during the fermentation, stabilization and storage as a result of co-precipitation with tartaric acid salts in a form of colloidal material, adsorption on yeast cell walls, elimination during filtration and fining or their participation in numerous chemical reactions forming numerous novel monomeric, oligomeric and polymeric compounds (Rentzsch et al., 2007). In particular, during winemaking and wine aging, anthocyanins may react with both fermentation metabolites and other grape and wine phenolic compounds, by means of cycloaddition to the $0-5$ and C-4 positions of the anthocyanins (He et al., 2006; Rentzsch et al., 2010; Oliveira et al., 2010; Blanco-Vega et al., 2011), thus generating new anthocyanin-derived stable pigments, namely pyranoanthocyanins which play an important role in color stabilization. In fact, these new pigments are responsible for the changes of red-purple color to orange hues since they possess more reddish-orange color compared to the native anthocyanins. Furthermore, non-anthocyanin phenolic compounds, especially hydroxycinnamic acids, flavan-3-ols and flavonols participate in copigmentation reactions acting as copigments of anthocyanins followed by formation of new pigments that stabilize the color of red wines.

In recent years many studies have been performed on the structure and formation mechanisms of these anthocyanin derivatives, as well as on the conditions that enable their formation (Somers, 1966, 1971; Jurd, 1967; Timberlake and Bridle, 1976; Fulcrand et al., 1996; Bakker and Timberlake, 1997; Remy et al., 2000; Wang et al., 2003). Different techniques have been used for phenolics analysis and determination of their molecular masses, such as: high-performance liquid chromatography (HPLC), most commonly used for separation of complex mixtures of phenolics, coupled to electrospray ionization mass spectrometry (ESI-MS) for structure characterization of wine components; matrix-assisted laser desorption/ionization-time of flight-mass spectrometry (MALDI-TOF-MS); nuclear magnetic resonance (NMR); or atmospheric pressure chemical ionization (APCI) (Jemal et al., 1998; Wang and Sporns, 1999; Mateus et al., 2004; Reed et al., 2005; Gomez-Alonso et al., 2007; Carpentieri et al., 2007; Spáčil et al., 2009; Blanco-Vega et al., 2011; Ivanova et al., 2011a,b; Ferrari et al., 2011).

The aim of this study was to determine the detailed phenolic profile of Vranec wine, as the most widespread and typical red variety for Macedonia and the Balkans, and Cabernet Sauvignon and Merlot wines, as world known and popular varieties, all produced in Tikveš wine region in Republic of Macedonia, in three vintages (2006, 2007 and 2008). HPLC-DAD coupled to ESI-MS (Ion Trap) was used to confirm the presence of phenolic compounds in wines and then, to quantify them. For the first time, we report a detailed quantitative composition of potential bioactive compounds and antioxidant activity in red Macedonian wines, we compare the different varieties and we gain data useful to oenological management. Also, this study reports for the first time data on the content of hydroxyphenyl-pyranoanthocyanins in Macedonian red wines.

\section{Materials and methods}

\subsection{Chemicals and reagents}

Sodium hydroxide (reagent grade), Trolox and 2,2-diphenyl-1picrylhydrazyl (DPPH) and hydrochloric acid were from Sigma Aldrich (St. Louis, MO, USA). Acetic acid (eluent additive for LCMS) and water (LC-MS Chromasolv ${ }^{\circledR}$ ) were obtained from Fluka (Buchs, Switzerland). Methanol (LC-MS Chromasolv ${ }^{\mathbb{R}}$ ) was purchased from Riedel-de Haën GmbH \& Co. (Seelze, Germany). Commercial standards from Phytolab (Vestenbergsgreuth, Germany) were used: malvidin 3-glucoside, quercetin 3-Oglucuronide, caftaric acid, caffeic acid, p-coumaric acid, transresveratrol, and trans-resveratrol-3-glucoside (trans-piceid). Commercial standards from Extrasynthese (Genay, France) were used: the 3-O-glucosides of quercetin, kaempferol, isorhamnetin and syringetin, the 3-O-galactosides of quercetin and syringetin and procyanidins B1 and B2. Standards of gallic acid, (+)-catechin, and (-)-epicatechin were supplied by Sigma (Tres Cantos, Madrid, Spain). Standards of pyranoathocyanins (vitisin A or 10-carboxypyranomalvidin-3-glucoside; pinotin A or 10-(4"')-monohydroxyphenyl)-pyanomalvidin-3-glucoside; and 10-( $3^{\prime \prime \prime}, 4^{\prime \prime \prime}$-dihydroxyphenyl)-pyranomalvidin-3-glucoside) were those obtained in a previous work (Rentzsch et al., 2010). The trans isomers of resveratrol and piceid (resveratrol 3-glucoside) were transformed into their respective cis isomers by UV-irradiation (366 nm light for $5 \mathrm{~min}$ in quartz vials) of solutions of the trans isomers in $25 \%$ $\mathrm{MeOH}$. All the standards were used for identification and quantification by means of calibration curves, covering the expected concentration ranges (usually $0-100 \mathrm{mg} / \mathrm{L}$, with the exception of malvidin 3-glucoside covering a range of $0-1000 \mathrm{mg} /$ L). When a standard was not available, the quantification was made using the calibration curve of the most similar compound: malvidin 3-glucoside was used for all anthocyanins; acylated pyranoanthocyanins as their respective non-acylated compounds; vitisin B derivatives as vitisin A; $p$-coumaric acid was used for trans- and cis-coutaric acids; ferulic acid was used for trans-fertaric acid; myricetin- and laricitrin-based flavonols as syringetin-glucoside; flavonol 3-glycosides with non-available standard as their corresponding 3-glucoside derivatives. All other solvents were of HPLC quality and all chemicals of analytical grade (>99\%). Water was of Milli-Q quality.

\subsection{Wine samples}

Grape berries used for this study were grown at the vineyards (altitude of $110-640 \mathrm{~m}$ ) of the TIKVEŠ winery (longitude: 22.0025341129, latitude: 41.435684159), the biggest winery in the Balkan, located in the Tikveš area, the most famous wine region in Republic of Macedonia. Grapes were cultivated at 30 ha, 10 ha and 6 ha vineyards of Vranec, Cabernet Sauvignon and Merlot, respectively and harvested at optimal technological maturity (20$22^{\circ}$ Brix). The distance between the rows was $2.3 \mathrm{~m}$ and distance between the vines was $1.1 \mathrm{~m}$. The average temperature in 2006, 2007 and 2008 calculated for 6 months (from June to December) was $15.6,14.1$ and $14.8{ }^{\circ} \mathrm{C}$, respectively, and the relative humidity was 66,67 and $68 \%$, respectively.

A total of 9 red wine samples from three $V$. vinifera varieties (Vranec, Merlot and Cabernet Sauvignon) from three different vintages (2006-2008) were investigated. In order to obtain representative samples for each wine variety and each vintage, 
all samples were prepared by mixing wines from three tanks produced with the same technological treatment. All wine samples were kindly provided by tikveš Winery, Kavadarci, Republic of Macedonia.

\subsection{Solid-phase extraction of non-anthocyanin phenolics in wine}

Before the HPLC analysis of non-anthocyanin phenolics, solid-phase extraction method was applied following the procedure published by Castillo-Muñoz et al. (2007). Thus, wines were diluted with $0.1 \mathrm{M} \mathrm{HCl}$ solution $(1: 1, \mathrm{~V} / \mathrm{V})$ before passing them through the SPE cartridges (Oasis MCX cartridges of $6 \mathrm{~mL}$ capacity filled with $500 \mathrm{mg}$ of adsorbent; Waters Corp., Milford, MA). The cartridges were conditioned with $5 \mathrm{~mL}$ of methanol and $5 \mathrm{~mL}$ of water and the diluted wine sample ( $3 \mathrm{~mL}$ of wine diluted with $3 \mathrm{~mL}$ of $0.1 \mathrm{M}$ hydrochloric acid solution) was introduced into the cartridge. $5 \mathrm{~mL}$ of $0.1 \mathrm{M}$ hydrochloric acid solution and $5 \mathrm{~mL}$ of water were used to wash the cartridge, followed by elution of the anthocyanin-free fraction with $3 \times 5 \mathrm{~mL}$ of methanol. The eluate containing non-anthocyanin phenolic compounds was dried in a rotary evaporator $\left(35^{\circ} \mathrm{C}\right)$ and re-dissolved in $3 \mathrm{~mL}$ of solvent $A$ used in the HPLC separation.

\subsection{HPLC-DAD-ESI-MS $S^{n}$ analysis}

An Agilent 1100 Series system (Agilent, Münster, Germany) coupled to DAD (G1315B) and a LC/MSD Trap VL (G2445 C VL) electrospray ionization mass spectrometry (ESI-MS ${ }^{n}$ ) system was used for the HPLC-DAD-ESI-MS ${ }^{n}$ analysis. An Agilent ChemStation (version B.01.03) was used for data processing. The mass spectra were processed with the Agilent LC/MS Trap software (version 5.3). HPLC-DAD-ESI-MS ${ }^{n}$ analyses of wines were performed according to the procedure previously described by Castillo-Muñoz et al. (2007 and 2009).

Thus, for analysis of anthocyanins and related pigments, samples were only diluted with $0.1 \mathrm{M} \mathrm{HCl}$ solution $(1: 4, \mathrm{~V} / \mathrm{V})$ and diluted samples $(50 \mu \mathrm{L})$ after filtration $(0.20 \mu \mathrm{m}$, polyester membrane, Chromafil PET 20/25, Macherey-Nägel, Düren, Germany) were directly injected into the HPLC system. Separation of the compounds was performed on a reversed-phase column Zorbax Eclipse XDB-C18 $(250 \times 4.6 \mathrm{~mm} ; 5 \mu \mathrm{m}$ particle size; Agilent, Germany), at a constant temperature of $40{ }^{\circ} \mathrm{C}$. The mobile phase consisted of water/acetonitrile/formic acid (87:3:10, V/V/V, solvent A) and water/acetonitrile/formic acid (40:50:10, V/V/V, solvent $B$ ) at flow rate of $0.63 \mathrm{~mL} \mathrm{~min}^{-1}$. Proportions of solvent $\mathrm{B}$ were as follows: $0 \mathrm{~min}, 6 \% ; 15 \mathrm{~min}, 30 \%$; $30 \mathrm{~min}, 50 \%$; $35 \mathrm{~min}, 60 \%$; $38 \mathrm{~min}, 60 \%$ and $46 \mathrm{~min}, 6 \%$.

For the ESI-MS ${ }^{n}$ analyses, ESI was operated in positive ionization mode. Nitrogen was used as drying gas with flow rate of $11 \mathrm{~L} / \mathrm{min}$ and drying temperature of $350{ }^{\circ} \mathrm{C}$. The pressure of the nebulizer was set at $65 \mathrm{psi}$, the capillary at $2500 \mathrm{~V}$, capillary exit offset at $70 \mathrm{~V}$, skimmer 1 at $20 \mathrm{~V}$; skimmer 2 at $6 \mathrm{~V}$ and the compound stability at $100 \%$. During the chromatographic run, the mass spectra of the eluate were recorded in the $m / z$ range of 50-1200. For quantification purposes, DAD chromatograms were recorded at $520 \mathrm{~nm}$ and the concentration of pigments was expressed as equivalents of malvidin-3-glucoside.

For the analysis of non-anthocyanin phenolic compounds (flavonols, gallic acid, flavan-3-ol monomers and dimers, hydroxycinnamic acid derivatives and stilbenes) the free-anthocyanin extract obtained after SPE was injected $(50 \mu \mathrm{L})$ into the aforementioned HPLC system. Chromatographic separation was performed on the same column as described for the anthocyanins, using positive ionization mode for the ESI (capillary $+2500 \mathrm{~V}$, compound stability $40 \%$ ) for the analysis of flavonols and flavan-3ols and negative ionization mode for the ESI (capillary $-2500 \mathrm{~V}$, compound stability 40\%) for gallic acid, hydroxycinnamic acid derivatives and stilbenes. The solvents for elution were: solvent $\mathrm{A}$ (acetonitrile/water/formic acid, 3:88.5:8.5, V/V/V), solvent B (acetonitrile/water/formic acid, 50:41.5:8.5, V/V/V), and solvent C (methanol/water/formic acid, 90:1.5:8.5, V/V/V). The flow rate was $0.63 \mathrm{~mL} \mathrm{~min}^{-1}$. The linear solvents gradient was: zero min, $96 \% \mathrm{~A}$ and $4 \% \mathrm{~B} ; 7 \mathrm{~min}, 96 \% \mathrm{~A}$ and $4 \% \mathrm{~B} ; 38 \mathrm{~min}, 70 \% \mathrm{~A}, 17 \% \mathrm{~B}$ and 13\% C; $52 \mathrm{~min}, 50 \%$ A, 30\% B and 20\% C; $52.5 \mathrm{~min}, 30 \% \mathrm{~A}, 40 \% \mathrm{~B}$ and $30 \%$ C; $57 \mathrm{~min}, 50 \% \mathrm{~B}$ and $50 \%$ C; $58 \mathrm{~min}, 50 \% \mathrm{~B}$ and 50\% C; $65 \mathrm{~min}$, $96 \% \mathrm{~A}$ and $4 \% \mathrm{~B}$. Flavonols were recorded at $360 \mathrm{~nm}$, flavan-3-ols at $280 \mathrm{~nm}$, and stilbenes and hydroxycinnamic acid derivatives at $320 \mathrm{~nm}$.

\subsection{Measurement of antioxidant activity}

The antioxidant activity of wines was determined using the DPPH method. This method uses 2,2-diphenyl-1-picrylhydrazyl (DPPH) radical with an absorbance maximum at $515 \mathrm{~nm}$ which disappears when the radical is reduced by reaction with an antioxidant or another radical (Brand-Williams et al., 1995), according to the following reactions:

$\mathrm{DPPH}^{\bullet}+\mathrm{AH} \rightarrow \mathrm{DPPH}-\mathrm{H}+\mathrm{A}^{\bullet}$

$\mathrm{DPPH}^{\bullet}+\mathrm{R}^{\bullet} \rightarrow \mathrm{DPPH}-\mathrm{R}$

Therefore, the disappearance of absorbance at $515 \mathrm{~nm}$ by action of an antioxidant substance in a methanolic solution, measured with a spectrophotometer, serves to determine the antioxidant activity of the tested sample (for example, wine).

Determination of the antioxidant activity in this study was performed following the procedure described by Brand-Williams et al. (1995). Thus, the wine samples were diluted with methanol $(1: 20, \mathrm{~V} / \mathrm{V})$ and $100 \mu \mathrm{L}$ of the diluted wine was added to $2.9 \mathrm{~mL}$ of a methanol solution of the radical DPPH (with concentration of $6 \times 10^{-5} \mathrm{M}$ ) and absorbance at $515 \mathrm{~nm}$ was measured after $25 \mathrm{~min}$ storage at room temperature. For determination of the antioxidant activity, a calibration curve was constructed using methanol solutions of Trolox with concentrations ranging from 0.19 to $0.93 \mathrm{mM}$.

\subsection{Analysis of color}

Analysis of color was performed by the CIELAB simplified method proposed by Negueruela's research group (Ayala et al., 1997). Before measurements, the $\mathrm{pH}$ of wine samples was adjusted to $\mathrm{pH} 3.6$ with solution of $2 \mathrm{M} \mathrm{NaOH}$. Direct measurement of the absorbance of the wines with adjusted $\mathrm{pH}$, at 420, 520, 570 and $630 \mathrm{~nm}$, was carried out using a Spectronic Genesys 5 spectrophotometer (Milton Roy, Co., Warminster, PA, USA) at the wavelength range between 280 to $700 \mathrm{~nm}$ and using a cuvette with $2 \mathrm{~mm}$ optical path against the blank-water. Calculations were made using the MSCV software developed by Negueruela's team to process the latter absorbance values (free downloadable at http:// www.unizar.es/negueruela/MSCV.es) and to obtain all the CIELAB parameters $\left(X, Y, Z, L^{*}, C^{*}, h^{*}, a^{*}, b^{*}\right)$.

\subsection{Statistical analysis}

Statistical treatments, including ANOVA (Tukey's test) and Factor analysis were performed using the XLSTAT Software, Version 2012.6.09, Addinsoft (Paris, France). Factor analysis was 
carried out to evaluate relationships among the groups of variables, e.g. concentration of anthocyanins, vitisins, hydroxyphenyl-pyranoanthocyanins, flavonols, hydroxycinnamic acid derivatives, stilbenes, antioxidant activity and CIELAB values $\left(L^{*}\right.$, $C^{*}$ and $h^{*}$ ).

\section{Results and discussion}

\subsection{Identification of phenolic compounds by HPLC-DAD-ESI-MS}

The HPLC-DAD-ESI-MS ${ }^{n}$ technique was used to determine the phenolic profile of the Vranec, Cabernet Sauvignon and Merlot wines produced in three different vintage years, 2006, 2007 and 2008. Different families of phenolic compounds were considered: anthocyanins, vitisins, hydroxyphenyl-pyranoanthocyanins, flavonols, hydroxycinnamic acids derivatives and stilbenes (retention time and MS data are given in Table 1). The assignment of the individual phenolic compounds was carried out by comparison of their UV/vis spectra and retention times with those of the available standards (presented in Section 2.1), as well as by comparing the ESI-MS and MS/MS data with the standards analyzed under the same experimental conditions and those found in the literature (Downey et al., 2003; Wu and Prior, 2005; Montealegre et al., 2006; Castillo-Muñoz et al., 2007; Blanco-Vega et al., 2011; Ivanova et al., $2011 \mathrm{a}, \mathrm{c})$. As observed in Table 1, 65 phenolic compounds were identified including 14 anthocyanins, 18 pyranoanthocyanins, 16 flavonols, 4 flavan-3-ols, 8 hydroxycinnamic acids and their derivatives and 4 stilbenes and one hydroxybenzoic acid. The UV/vis chromatograms of Vranec, Cabernet Sauvignon and Merlot wines (vintage 2008) recorded at 520, 360 and $320 \mathrm{~nm}$ are presented in Figs. 1-3, respectively.

Anthocyanins. The presence of 3-glucoside, 3-acetylglucoside and 3-p-coumaroylglucoside derivatives of delphinidin, cyanidin, petunidin, peonidin and malvidin was confirmed in the analyzed wines. The non-acylated anthocyanidin 3-monoglucosides have similar mass spectra characterized with two signals, molecular ion $\mathrm{M}^{+}$and aglycone fragment $[\mathrm{M}-162]^{+}$obtained after elimination of a glucose moiety. The 3-acetylglucoside and 3-p-coumaroylglucoside derivatives of the anthocyanins were identified in a similar way, characterized with molecular ion $\mathrm{M}^{+}$and $[\mathrm{M}-204]^{+}$fragment corresponding to elimination of an acetylglucose group and molecular ion $\mathrm{M}^{+}$and fragment ion $[\mathrm{M}-308]^{+}$as a result of loss of the entire $p$-coumaroylglucose group, respectively (De Villers et al., 2004; Rubilar et al., 2007; Chinnici et al., 2009; Ivanova et al., 2011a,c).

Pyranoanthocyanins. The pyranoanthocyanins derived from pyruvic acid are called 10-carboxy-pyranoanthocyanins or A-type vitisins and were detected in Vranec, Cabernet Sauvignon and Merlot wines. Thus, 10-carboxy-pyranomalvidin-3-glucoside (viti$\sin$ A), 10-carboxy-pyranomalvidin-3-acetylglucoside (acetyl-viti$\sin A$ ) and 10-carboxy-pyranomalvidin-3-p-coumaroylglucoside ( $p$-coumaroyl-vitisin A) were identified according to their molecular ions $\left(\mathrm{M}^{+}\right)$and main fragments in their mass spectra (Table 1). These three compounds have the same characteristic fragment which corresponds to 10-carboxy-pyranomalvidin aglycone $\left([\mathrm{M}+\mathrm{H}]^{+}=m / z\right.$ 399) (Ivanova et al., 2011a). Another A-type vitisin was identified as 10-carboxy-pyranopeonidin-3-glucoside presenting a molecular ion at $m / z 531$ and a fragment ion at $m / z 369$, corresponding to elimination of a glucoside moiety (162 u). Another group of pyranoanthocyanins (called B-type vitisins) resulting from cycloaddition reaction between anthocyanins and acetaldehyde were also detected in the wines. Thus, compounds with molecular signals $\mathrm{M}^{+}$at $m / z$ 517, 559 and 663 were identified as pyranomalvidin-3-glucoside (vitisin B), pyranomalvidin-3acetylglucoside (acetyl-vitisin B) and pyranomalvidin-3-p-coumaroylglucoside ( $p$-coumaroyl-vitisin $\mathrm{B}$ ) all producing a fragment ion at $m / z 355$ by loss of glucoside ( $162 \mathrm{u}$ ), acetylgucoside ( $204 \mathrm{u}$ ) and $p$-coumaroylglucoside (308 u) groups, respectively.

Two compounds with same molecular ions at $m / z 805$ were detected in the wines and tentatively identified as 10-flavanylpyranoanthocyanins (reaction products between anthocyanins and 8-vinylflavanols, released from the cleavage of previously formed ethyl bridged flavan-3-ol oligomers), namely 10-catechinpyranomalvidin-3-glucoside and 10-epicatechin-pyranomalvidin3-glucoside (Mateus et al., 2003). The fragmentation of the molecular ion $(m / z$ 805) produced fragment ions at $m / z 643$ and 491 , the first one corresponding to elimination of a glucose moiety $(162 \mathrm{u})$ and the second one to Retro Diels-Alder (RDA) fission of the $\mathrm{B}$ ring of the flavan-3-ol moiety, characterized by loss of $152 \mathrm{u}$. In addition, the components with $\mathrm{m} / \mathrm{z} 1093$ (fragment ions: $\mathrm{m} / \mathrm{z}$ 931, 803) and $m / z 1135$ (fragment ions: $m / z$ 931, 845) were tentatively identified as 10 -(procyanidin dimer)-pyranomalvidin3-glucoside and 10-(procyanidin dimer)-pyranomalvidin-3-acetylglucoside, respectively (He et al., 2006; Stefova and Ivanova, 2011d). Fragmentation of the molecular ions yielded aglycone cations at $m / z 931$ as a result of loss of glucose and acetyglucose moieties, respectively. The fragments at $\mathrm{m} / \mathrm{z} 803$ and 845 , for both components respectively, were suggested to be formed by cleavage of the interflavonoid bond of the procyanidin dimer moieties.

Hydroxyphenyl-pyranoanthocyanins produced in the reaction of caffeic acid with different anthocyanins were found for the first time in the Macedonian wines. Compounds with molecular ions at $m / z 625,667$ and 771 were identified as $10-\left(3^{\prime \prime \prime}, 4^{\prime \prime \prime}\right.$-dihydroxyphenyl)-pyranomalvidin-3-glucoside (10-DHP-pyrm-3-glc, also known as pinotin A) (Rentzsch et al., 2010), 10-( $3^{\prime \prime \prime}, 4^{\prime \prime \prime}$-dihydroxyphenyl)-pyrano malvidin-3-acetylglucoside (10-DHP-pymv-3acglc), and 10-( $3^{\prime \prime \prime}, 4^{\prime \prime \prime}$-dihydroxyphenyl)-pyrano malvidin-3-pcoumaroylglucoside (10-DHP-pymv-3-cmglc), respectively. Hydroxyphenyl-pyranoanthocyanins originating from the reaction of $p$-coumaric acid (or its corresponding 4-vinylphenol) and different anthocyanins were also detected in the wines. Thus, compounds with molecular ions at $m / z$ 609, 651 and 755 were tentatively assigned as $10-\left(4^{\prime \prime \prime}\right.$-monohydroxyphenyl $)$ derivatives (10-MHP) of pyranomalvidin-3-glucoside, pyranomalvidin-3acetylglucoside and pyranomalvidin-3-p-coumaroylglucoside, respectively. The presence of hydroxyphenyl-pyranoanthocyanins has already been reported in wines (Mateus et al., 2002; Wang et al., 2003; Alcalde-Eon et al., 2006; Rentzsch et al., 2007; BlancoVega et al., 2011).

Acetaldehyde-mediated condensation adducts between anthocyanins and (epi)catechin leads to ethyl-bridged pigments (Timberlake and Bridle, 1976) and only one compound from this group was detected in wines and identified as (epi)catechin-ethylmalvidin-3-p-coumaroylglucoside. This compound presented a molecular ion at $m / z$ 955. Fragmentation of this molecular ion produced fragment ions at $m / z 665$ and 357 . The first fragment $(m / z$ 665) corresponds to elimination of an (epi)catechin molecule $(290 \mathrm{u})$ and the second fragment is a result of a loss of $p$-coumaroylglucose group (308 u).

Flavonols. The aglycones kaempferol $\left([\mathrm{M}+\mathrm{H}]^{+}\right.$at $m / z$ 287), quercetin $\left([\mathrm{M}+\mathrm{H}]^{+}\right.$at $\left.m / z 303\right)$, isorhamnetin $\left([\mathrm{M}+\mathrm{H}]^{+}\right.$at $\left.m / z 317\right)$, myricetin $\left([\mathrm{M}+\mathrm{H}]^{+}\right.$at $\left.m / z 319\right)$, laricitrin $\left([\mathrm{M}+\mathrm{H}]^{+}\right.$at $\left.m / z 333\right)$ and syringetin $\left([\mathrm{M}+\mathrm{H}]^{+}\right.$at $m / z$ 347) were detected in the analyzed wines. The 3-glucoside derivatives of the six aforementioned flavonol aglycones were identified in Vranec, Cabernet Sauvignon and Merlot wines on the basis of their pseudomolecular ions $\left([\mathrm{M}+\mathrm{H}]^{+}\right)$and fragment ion $\left([\mathrm{M}+\mathrm{H}-162]^{+}\right)$signals corresponding to elimination of a glucose moiety (Castillo-Muñoz et al., 2007). Kaempferol-3-glucuronide, quercetin-3-glucuronide and myricetin-3-glucuronide were also present in the wines, identified by the expected loss of $176 \mathrm{u}\left([\mathrm{M}+\mathrm{H}-176]^{+}\right)$, corresponding to elimination of a glucuronide moiety. Myricetin-3-galactoside, which is 
Table 1

Phenolic compounds identified in Vranec, Cabernet Sauvignon and Merlot wines by HPLC-ESI-MS ${ }^{n}$ analysis.

\begin{tabular}{|c|c|c|c|}
\hline Phenolics & $t_{\mathrm{r}}(\min )$ & $\operatorname{MS}(m / z)$ & MS/MS $(m / z)$ \\
\hline Anthocyanins & & $\mathrm{M}^{+}$ & Fragment ion \\
\hline \multicolumn{4}{|l|}{ Non-acylated glucosides } \\
\hline Dp-3-glc & 9.89 & 465 & 303 \\
\hline Cy-3-glc & 11.53 & 449 & 287 \\
\hline Pt-3-glc & 12.85 & 479 & 317 \\
\hline Pn-3-glc & 14.62 & 463 & 301 \\
\hline Mv-3-glc & 15.88 & 493 & 331 \\
\hline \multicolumn{4}{|l|}{ Acetylglucosides } \\
\hline Dp-3-acetylglc & 16.70 & 507 & 303 \\
\hline Pt-3-acetylglc & 20.56 & 521 & 317 \\
\hline Pn-3-acetylglc & 23.13 & 505 & 301 \\
\hline Mv-3-acetylglc & 24.35 & 535 & 331 \\
\hline \multicolumn{4}{|l|}{ p-Coumaroylglucosides } \\
\hline Dp-3-p-coumglc & 22.50 & 611 & 303 \\
\hline Cy-3-p-coumglc & 24.98 & 595 & 287 \\
\hline Pt-3-p-coumglc & 26.30 & 625 & 317 \\
\hline Pn-3-p-coumglc & 28.98 & 609 & 301 \\
\hline Mv-3-p-coumglc & 28.90 & 639 & 331 \\
\hline \multicolumn{4}{|l|}{ Pyranoanthocyanins } \\
\hline Vitisin-A & 18.04 & 561 & 399 \\
\hline Ac-vitisin-A & 19.66 & 603 & 399 \\
\hline$p-C m$-vitisin-A & 23.43 & 707 & 399 \\
\hline Vitisin-B & 19.16 & 517 & 355 \\
\hline Ac-vitisin-B & 21.28 & 559 & 355 \\
\hline p-Cm-vitisin-B & 24.78 & 663 & 355 \\
\hline 10-carboxy-pyranoPn-3-glc & & 531 & 369 \\
\hline 10-catechin-pyranoMv-3-glc & & 805 & 643,491 \\
\hline 10-epicatechin-pyranoMv-3-glc & & 805 & 643,491 \\
\hline $\begin{array}{l}\text { 10-(procyanidin dimer)- } \\
\text { pyranoMv-3-glc }\end{array}$ & & 1093 & 931,803 \\
\hline $\begin{array}{l}\text { 10-(procyanidin dimer)- } \\
\text { pyranoMv-3-acetylglc }\end{array}$ & & 1135 & 931,845 \\
\hline $\begin{array}{l}\text { 10-DHP-pymv-3-glc } \\
\text { (pinotin A) }\end{array}$ & 30.85 & 625 & 463 \\
\hline 10-DHP-pymv-3-acglc & 32.61 & 667 & 463 \\
\hline 10-DHP-pymv-3-cmglc & 35.26 & 771 & 447 \\
\hline 10-MHP-pymv-3-glc & 33.54 & 609 & 447 \\
\hline 10-MHP-pymv-3-acglc & 35.91 & 651 & 447 \\
\hline 10-MHP-pymv-3-cmglc & 37.98 & 755 & 447 \\
\hline $\begin{array}{l}\text { (epi)catechin-ethyl-Mv-3- } \\
\text { p-coumaroylglc }\end{array}$ & & 955 & 665,357 \\
\hline Phenolics & $t_{\mathrm{r}}(\min )$ & $\operatorname{MS}(m / z)$ & MS/MS $(m / z)$ \\
\hline Flavonols & & {$[\mathrm{M}+\mathrm{H}]^{+}$} & Fragment ion \\
\hline M-glcU & 22.56 & 495 & 319 \\
\hline M-gal & 23.04 & 481 & 319 \\
\hline M-glc & 23.79 & 481 & 319 \\
\hline Q-glcU & 29.25 & 479 & 303 \\
\hline Q-glc & 30.36 & 465 & 303 \\
\hline L-glc & 32.94 & 495 & 333 \\
\hline $\mathrm{M}$ & 34.08 & 319 & \\
\hline K-glcU & 35.51 & 463 & 287 \\
\hline K-glc & 36.61 & 449 & 287 \\
\hline I-glc & 39.58 & 479 & 317 \\
\hline S-glc & 41.30 & 509 & 347 \\
\hline $\mathrm{Q}$ & 44.77 & 303 & \\
\hline $\mathrm{L}$ & 48.44 & 333 & \\
\hline K & 52.73 & 287 & \\
\hline I & 56.03 & 317 & \\
\hline $\mathrm{S}$ & 57.41 & 347 & \\
\hline \multicolumn{4}{|l|}{ Flavan-3-ols } \\
\hline Procyanidin B2 & 7.76 & 579 & 291 \\
\hline Catechin & 8.61 & 291 & $\begin{array}{l}273,165,139, \\
123\end{array}$ \\
\hline Procyanidin B1 & 11.20 & 579 & 291 \\
\hline Epicatechin & 14.94 & 291 & $\begin{array}{l}273,165,139, \\
123\end{array}$ \\
\hline Phenolics & $t_{\mathrm{r}}(\min )$ & $\operatorname{MS}(m / z)$ & MS/MS $(m / z)$ \\
\hline $\begin{array}{l}\text { Hydroxycinnamic } \\
\text { acids derivatives }\end{array}$ & & {$[\mathrm{M}-\mathrm{H}]^{-}$} & Fragment ions \\
\hline
\end{tabular}

trans-Caftaric acid detected for the first time in the Macedonian wines, was also identified, showing a molecular ion at $\mathrm{m} / \mathrm{z} 481$ and a fragment ion at $m / z 319$ resulting from elimination of a galactose moiety (162 u). The assignment of the 3-glucoside and 3-galactoside of myricetin (both compounds having identical MS and MS/MS spectra) was based on their different retention times (Castillo-Muñoz et al., 2009).

Flavan-3-ols. Flavan-3-ol monomers, $((+)$-catechin and (-)epicatechin $\left([\mathrm{M}+\mathrm{H}]^{+}=m / z 291\right)$, and dimers, namely procyanidins $\mathrm{B} 1$ and $\mathrm{B} 2\left([\mathrm{M}-\mathrm{H}]^{+}=m / z 579\right)$ were detected in all wines. The two peaks appearing at $8.61 \mathrm{~min}$ and $14.94 \mathrm{~min}$, showing the same pseudomolecular ion at $m / z 291$, were identified as catechin and epicatechin, respectively, both producing the fragment ions at $\mathrm{m} / \mathrm{z}$ $273,165,139,123$ (Cren-Olive, 2000). The fragment ion at $\mathrm{m} / \mathrm{z} 273$ corresponds to elimination of water molecule, while the one at $\mathrm{m} / \mathrm{z}$ 165 corresponds to loss of a phloroglucinol molecule ([M+H$\left.126]^{-}\right)$. The fragment ion at $m / z 139$ results from Retro-Diels-Alder (RDA) rearrangement on the C-ring of catechin and epicatechin derivatives and as a result of that cleavage, two possible fragment ions are formed: $\mathrm{m} / \mathrm{z} 139$ by a loss of $152 \mathrm{Da}$ and $\mathrm{m} / \mathrm{z} 123$ is a B-ring product ion. The two compounds eluting at 7.76 and $11.20 \mathrm{~min}$, showing pseudomolecular ions at $m / z 577$ (fragments ions at $m / z$ : 291 ), were tentatively identified as flavan-3-ol dimmers. The fragment ions at $m / z 291$ correspond to the terminal flavan-3-ol unit of the dimers.

Hydroxycinnamic acids derivatives. From the group of hydroxycinnamic acid derivatives, the following compounds were detected in the wines: trans-caftaric (caffeoyltartaric) acid with a pseudomolecular ion $\left([\mathrm{M}-\mathrm{H}]^{-}\right)$at $\mathrm{m} / \mathrm{z} 311$ and fragment ions at $\mathrm{m} / \mathrm{z} 179$ and 149 ); trans- and cis -coutaric (coumaroyltartaric) acid at $m / z 295\left([\mathrm{M}-\mathrm{H}]^{-}\right.$, fragment ion at $\left.\mathrm{m} / \mathrm{z} 163\right)$, trans-fertaric (feruloyltartaric) acid at $\mathrm{m} / \mathrm{z} 325\left([\mathrm{M}-\mathrm{H}]^{-}\right.$, fragment ion at $\mathrm{m} / \mathrm{z}$ 193). These four compounds give rise to the same characteristic fragment ion $[\mathrm{M}-\mathrm{H}-132]^{-}$corresponding to loss of a tartaric acid residue (Ivanova et al., 2011a). Caffeic acid was the only hydroxycinnamic acid detected in wines showing molecular ion at $m / z 179$ and fragment ion at $m / z 135$, corresponding to loss of $\mathrm{CO}_{2}$ group from the acid. Furthermore, ethyl caffeate at $\mathrm{m} / \mathrm{z} 207$ and ethyl coumarate at $\mathrm{m} / \mathrm{z} 191$ were also detected in Vranec,

\begin{tabular}{|c|c|c|c|}
\hline $\begin{array}{l}\text { Phenolics } \\
\text { Hydroxycinnamic } \\
\text { acids derivatives }\end{array}$ & $t_{\mathrm{r}}(\min )$ & $\begin{array}{l}\mathrm{MS}(m / z) \\
{[\mathrm{M}-\mathrm{H}]^{-}}\end{array}$ & $\begin{array}{l}\text { MS/MS }(m / z) \\
\text { Fragment ions }\end{array}$ \\
\hline $\begin{array}{l}\text { trans-Coutaric acid } \\
\text { cis-Coutaric acid } \\
\text { Caffeic acid } \\
\text { trans-Fertaric acid } \\
\text { p-Coumaric acid } \\
\text { Ethyl caffeate } \\
\text { Ethyl coumarate }\end{array}$ & $\begin{array}{r}9.77 \\
10.01 \\
12.24 \\
13.21 \\
19.41 \\
44.60 \\
53.58\end{array}$ & $\begin{array}{l}295 \\
295 \\
179 \\
325 \\
147 \\
207 \\
191\end{array}$ & $\begin{array}{l}163 \\
163 \\
135 \\
193 \\
103 \\
179 \\
147\end{array}$ \\
\hline $\begin{array}{l}\text { Stilbenes } \\
\text { trans-piceid } \\
\text { trans-resveratrol } \\
\text { cis-piceid } \\
\text { cis-resveratrol }\end{array}$ & $\begin{array}{l}24.47 \\
33.92 \\
34.28 \\
40.67\end{array}$ & $\begin{array}{l}389 \\
227 \\
389 \\
227\end{array}$ & $\begin{array}{l}227 \\
227\end{array}$ \\
\hline $\begin{array}{l}\text { Hydroxybenzoic acids } \\
\text { Gallic acid }\end{array}$ & 5.69 & 169 & 125 \\
\hline
\end{tabular}

Dp, delphinidin; Cy, cyanidin; Pt, petunidin; Pn, peonidin; Mv, malvidin; Cat, catechin; Epicat, epicatechin; K, kaempferol; Q quercetin; I, isorhamnetin; M, myricetin; L, laricitrin; S, syringetin; glc, 3-glucoside; acglc, 3-(6"-acetyl)glucoside; cmglc, 3-(6"-coumaroyl)-glucoside; glcU, 3-glucuronide; gal, 3-glalactoside 10-MHP, 10-(4'"'-monohydroxyphenyl); 10-DHP, 10-( $3^{\prime \prime \prime}, 4^{\prime \prime \prime}$-dihydroxyphenyl); pymv, pyranomalvidin; vitisin A, 10-carboxy-pyrmv-3-glc; vitisin $\mathrm{B}, 10-\mathrm{H}-$ pymv-3-glc; A-type vitisin, 10-carboxy-pyranoanthocyanins.

nd, not detected.

The details on the HPLC-ESI-MS-MS ${ }^{n}$ method are described in Section 2.4 


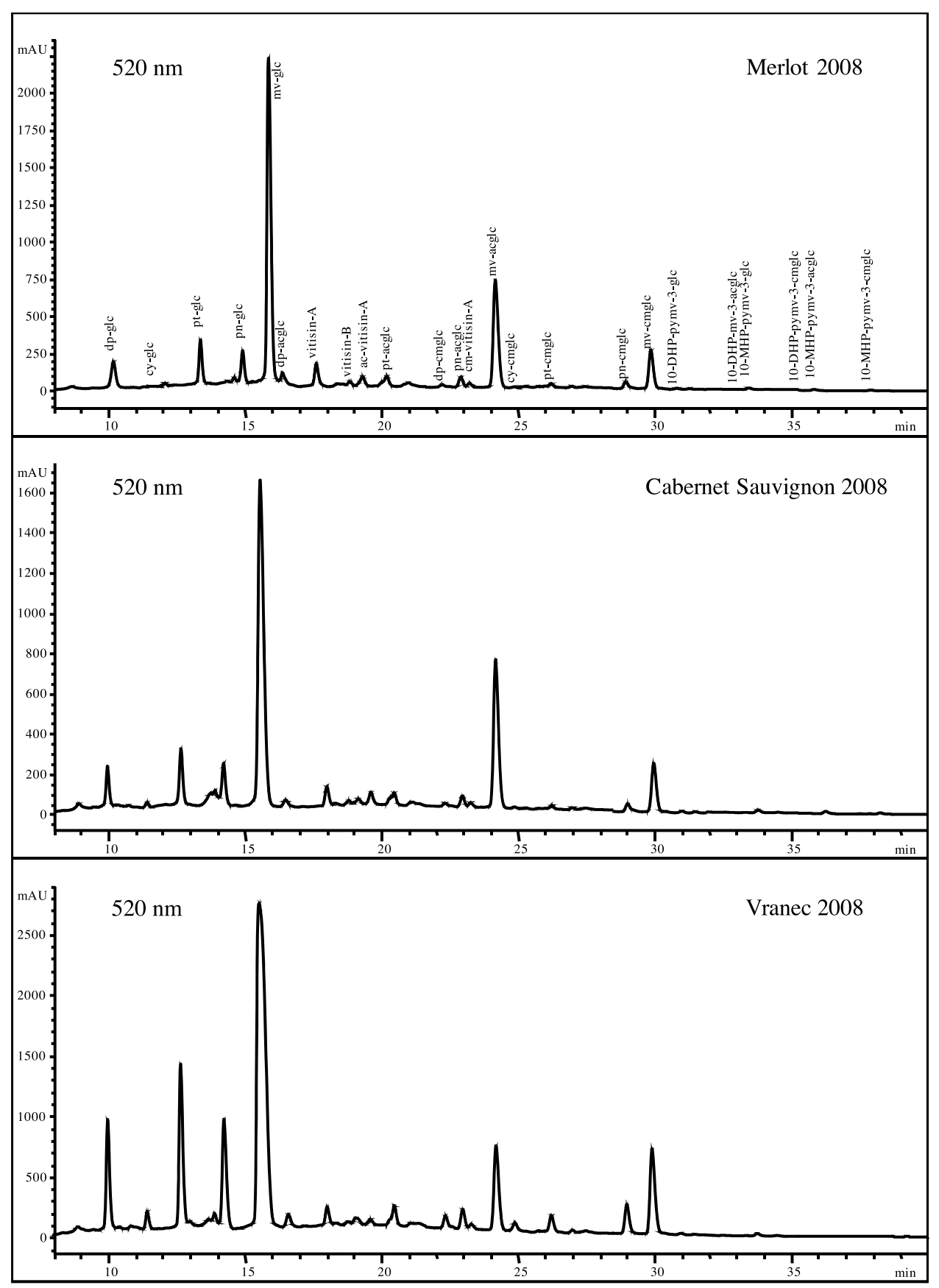

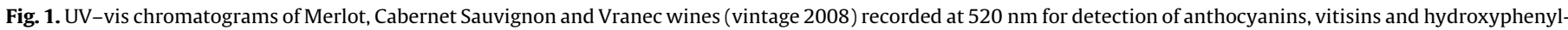

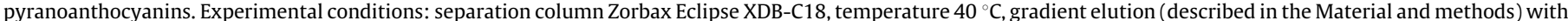

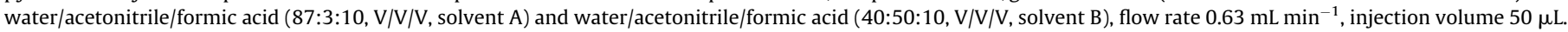

Cabernet Sauvignon and Merlot wines. Both compounds showed a characteristic fragment loss of $28 \mathrm{u}$ (ethyl moiety).

Hydroxybenzoic acids. With regard to hydrozybenzoic acids, only gallic acid was detected by ESI-MS, presenting ion at $m / z 169$ and fragment ion $[\mathrm{M}-\mathrm{H}]^{-}$at $m / z 112$ corresponding to loss of $\mathrm{CO}_{2}$ group $(44 \mathrm{u})$ from the acid.

Stilbenes. Cis and trans-resveratrol-3-glucosides (cisand transpiceid) and cisand trans-resveratrol were detected in the wines by ESI-MS, giving pseudomolecular ions at $m / z 389$ and $m / z 227$, respectively. The pseudo-molecular ion of trans/cis-resveratrol glucoside (trans/cis-piceid) $[\mathrm{M}-\mathrm{H}]^{-}$at $\mathrm{m} / \mathrm{z} 389$ produced a fragment ion $[\mathrm{M}-\mathrm{H}]^{-}$at $m / z 227$ corresponding to free resveratrol by loss of the glucose moiety (Ivanova et al., 2011a).

\subsection{Quantitative analysis}

The quantitative analysis of phenolic compounds in Vranec, Cabernet Sauvignon and Merlot wines was performed using the peak areas in the HPLC-DAD chromatograms recorded at $520 \mathrm{~nm}$ (for anthocyanins, vitisins and hydroxyphenyl-pyranoanthocyanins), $360 \mathrm{~nm}$ (for flavonols), $320 \mathrm{~nm}$ (for hydroxycinnamic acids derivatives and stilbenes) and 280 (for gallic acid and flavan-3-ols). Since wines were produced in three different vintages, it is expected that the storage conditions could influence the phenolic composition of the wines. Moreover, the meteorological conditions, as well as the technological practices applied during winemaking, also could affect the phenolic content of the wines, 

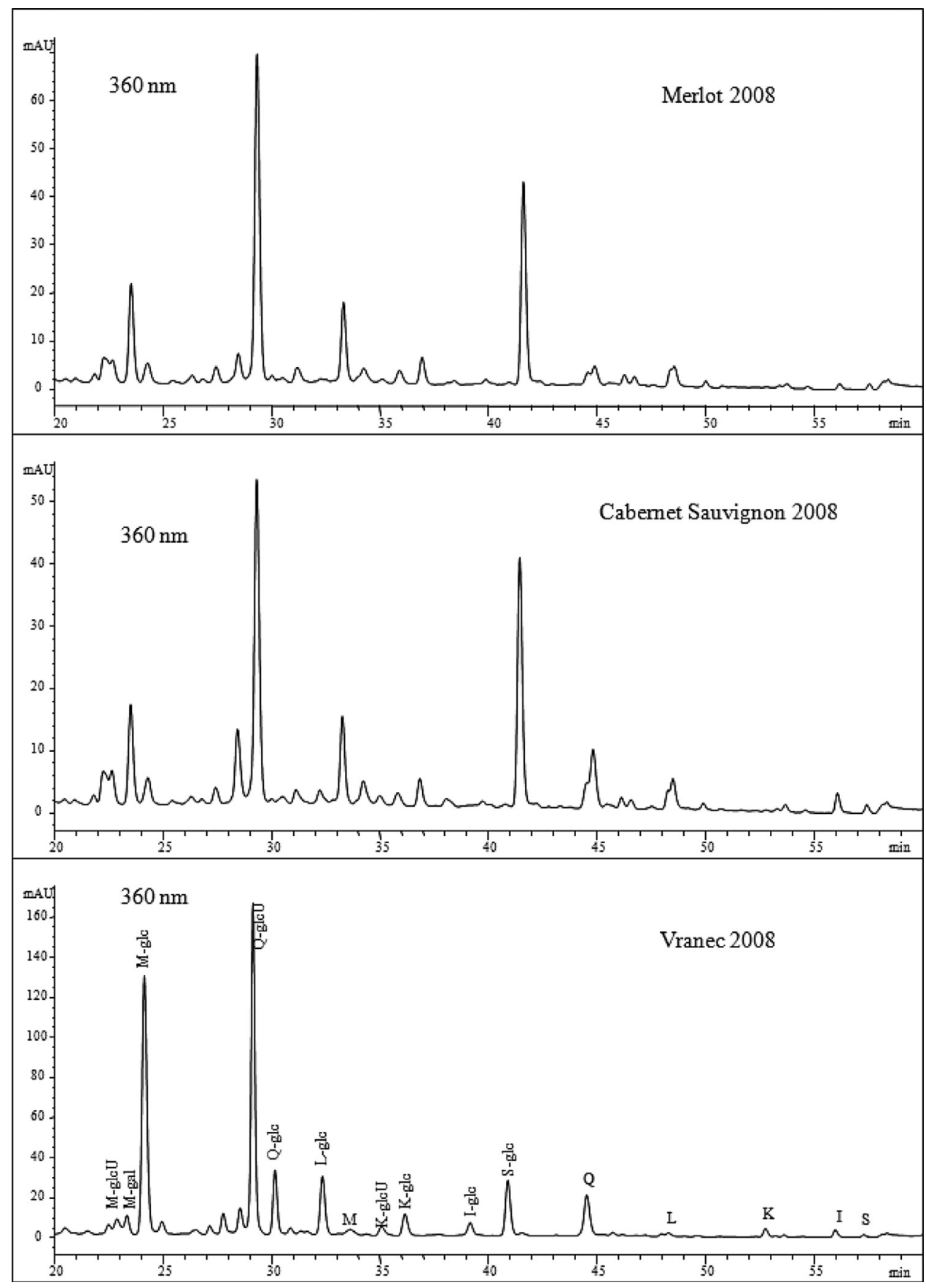

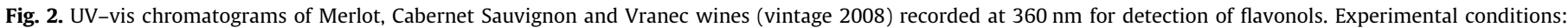

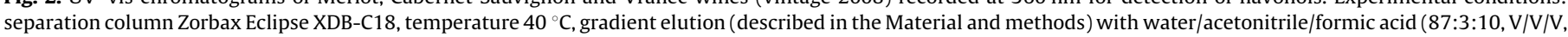
solvent $\mathrm{A}$ ) and water/acetonitrile/formic acid (40:50:10, V/V/V, solvent B), flow rate $0.63 \mathrm{~mL} \mathrm{~min}^{-1}$, injection volume $50 \mu \mathrm{L}$.

depending on the grape characteristics at the moment of harvest and their changes from year to year (Bautista-Ortín et al., 2007). Vranec wine contained mainly malvidin-3-glucoside $(47-50 \%$, on a molar basis) the dominant anthocyanin as expected for the most $V$. vinifera cultivars, followed by petunidin-3-glucoside (11-14\%, on a molar basis) and peonidin-3-glucoside (8-10\%, on a molar basis). Similarly, Merlot and Cabernet Sauvignon contained the highest amount of malvidin-3-glucoside (48-55\% and 45-52\%, respectively, on a molar basis) (Table 2). With regards to vitisins, vitisin A was the dominant component in all wines from all three years of production, present in relatively high amount $(40-70 \%$ on a molar basis), followed by acetyl-vitisin A and $p$-coumaroyl-vitisin A. The highest percentage of this component was noticed in Vranec and Cabernet Sauvignon wines from 2006 and Merlot from 2007 (Table 2). Since this compound is formed during the alcoholic fermentation by reaction of pyruvic acid and malvidin-3-glucoside, the maximum content of vitisin A was reached after three years of storage, probably due to the availability of pyruvic acid (Rentzsch et al., 2010).

From the group of hydroxyphenyl-pyranoanthocyanins, 10DHP-pyranomalvidin-3-glucoside (pinotin A) and 10-MHP-pyranomalvidin-3-glucoside were the dominant compounds present in range from 2 to $45 \%$ and 38 to 55\%, respectively (on a molar basis) (Table 2). Highest amount for both components was observed in 

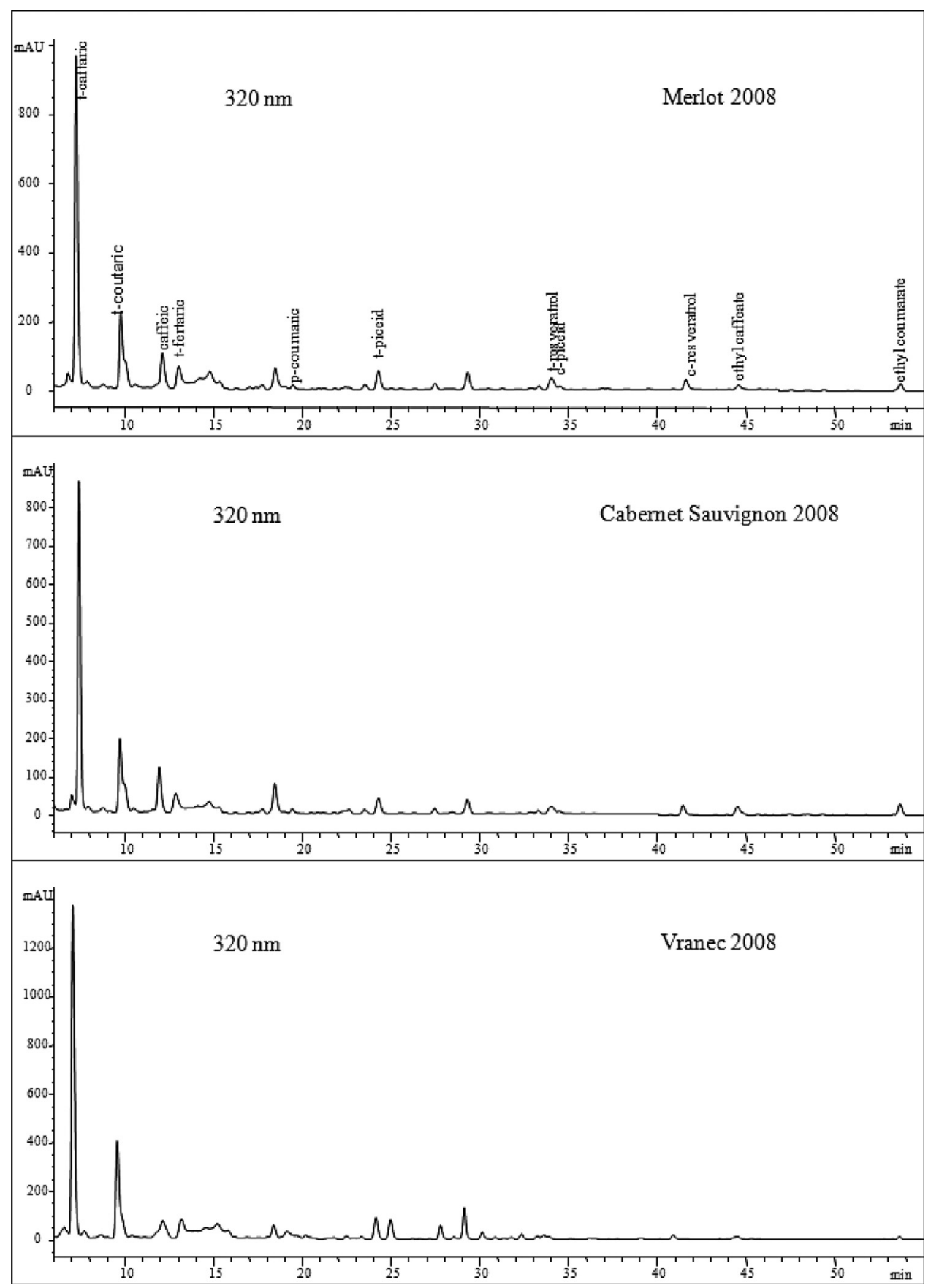

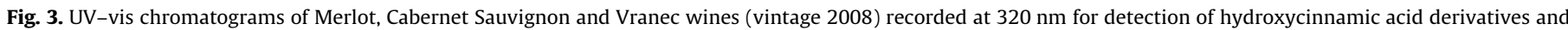

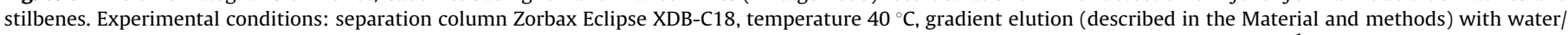
acetonitrile/formic acid (87:3:10, V/V/V, solvent $\mathrm{A})$ and water/acetonitrile/formic acid (40:50:10, $\mathrm{V} / \mathrm{V} / \mathrm{V}$, solvent $\mathrm{B})$, flow rate $0.63 \mathrm{~mL}$ min ${ }^{-1}$, injection volume $50 \mu \mathrm{L}$.

Vranec wines from 2006 and 2007 and Cabernet Sauvignon from 2006, but for Merlot practically no differences were observed between the years of production. Since these compounds are formed exclusively by direct reaction of anthocyanins and hydroxycinnamic acids after the completion alcoholic fermentation, their content was expected to increase during wine aging, as previously reported for Pinotage and Tempranilo wines (Schwarz et al., 2004; Rentzsch et al., 2010). To the best of our knowledge, this is the first raport for the content of hydroxyphenylpyranoanthocyanins in Macedonian wines.

Flavonols were found as the original ones from grape as 3-glycosides and also as free aglycones released after hydrolysis
(Castillo-Muñoz et al., 2007). Quercetin-type flavonols were dominant in all wines. In Vranec wines, myricetin-type and quercetin-type accounted as the main flavonols and the importance of the latter increased in more aged wines (Table 3 ). It is important to consider that flavonol glycosides are not homogeneously hydrolyzed in the wine and some specific compounds (e.g., quercetin-3-glucuronide) are quite resistant to hydrolysis (Castillo-Muñoz et al., 2007). In addition, flavonol aglycones are quite insoluble in wine and can precipitate, and myricetin derivatives are easily oxidizable compounds. As a consequence, quercetin-3-glucuronide was the dominant flavonol found in all wines, followed by quercetin and syringetin-3-glucoside (Table 3 ). 
Table 2

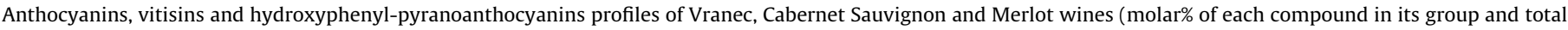
content of each group of compounds in $\mathrm{mg} / \mathrm{L}$ ).

\begin{tabular}{|c|c|c|c|c|c|c|c|c|c|}
\hline \multirow[t]{2}{*}{ Compounds/Wines } & \multicolumn{3}{|l|}{ Vranec } & \multicolumn{3}{|c|}{ Cabernet Sauvignon } & \multicolumn{3}{|l|}{ Merlot } \\
\hline & 2006 & 2007 & 2008 & 2006 & 2007 & 2008 & 2006 & 2007 & 2008 \\
\hline \multicolumn{10}{|l|}{ Anthocyanins } \\
\hline Dp-3-glc & $10.9 \pm 0.09$ & $7.37 \pm 0.05$ & $6.73 \pm 0.05$ & $6.17 \pm 0.05$ & $4.84 \pm 0.04$ & $3.86 \pm 0.03$ & $6.39 \pm 0.05$ & $5.54 \pm 0.03$ & $4.83 \pm 0.03$ \\
\hline Cy-3-glc & $2.34 \pm 0.02$ & $2.09 \pm 0.02$ & $1.03 \pm 0.01$ & $2.22 \pm 0.02$ & $0.51 \pm 0.01$ & $0.48 \pm 0.01$ & $0.77 \pm 0.01$ & $0.88 \pm 0.01$ & $0.52 \pm 0.01$ \\
\hline Pt-3-glc & $14.0 \pm 0.11$ & $10.6 \pm 0.10$ & $10.9 \pm 0.09$ & $10.4 \pm 0.08$ & $6.03 \pm 0.05$ & $5.87 \pm 0.04$ & $6.78 \pm 0.06$ & $7.68 \pm 0.06$ & $5.74 \pm 0.03$ \\
\hline Pn-3-glc & $10.1 \pm 0.09$ & $9.34 \pm 0.08$ & $8.10 \pm 0.08$ & $10.6 \pm 0.08$ & $4.49 \pm 0.04$ & $4.79 \pm 0.04$ & $5.61 \pm 0.04$ & $6.49 \pm 0.05$ & $4.51 \pm 0.02$ \\
\hline Mv-3-glc & $47.6 \pm 0.39$ & $50.2 \pm 0.42$ & $48.7 \pm 0.45$ & $44.9 \pm 0.39$ & $50.8 \pm 0.47$ & $51.7 \pm 0.46$ & $54.5 \pm 0.62$ & $48.2 \pm 0.52$ & $48.9 \pm 0.55$ \\
\hline Dp-3-acglc & $2.51 \pm 0.02$ & $1.74 \pm 0.02$ & $1.12 \pm 0.01$ & $0.99 \pm 0.01$ & $1.22 \pm 0.01$ & $0.94 \pm 0.01$ & $1.35 \pm 0.02$ & $2.11 \pm 0.03$ & $1.83 \pm 0.01$ \\
\hline Pt-3-acglc & $0.47 \pm 0.01$ & $0.93 \pm 0.01$ & $1.54 \pm 0.01$ & $1.54 \pm 0.01$ & $1.98 \pm 0.01$ & $1.48 \pm 0.01$ & $1.14 \pm 0.01$ & $1.57 \pm 0.02$ & $1.63 \pm 0.01$ \\
\hline Pn-3-acglc & $0.71 \pm 0.01$ & $1.14 \pm 0.01$ & $1.47 \pm 0.01$ & $1.43 \pm 0.01$ & $2.03 \pm 0.02$ & $1.25 \pm 0.01$ & $1.27 \pm 0.01$ & $2.50 \pm 0.02$ & $1.98 \pm 0.02$ \\
\hline Mv-3-acglc & $3.13 \pm 0.02$ & $5.54 \pm 0.04$ & $7.24 \pm 0.06$ & $7.08 \pm 0.06$ & $20.7 \pm 0.19$ & $20.3 \pm 0.17$ & $14.1 \pm 0.11$ & $14.5 \pm 0.09$ & $20.7 \pm 0.38$ \\
\hline Dp-3-cmglc & $0.65 \pm 0.01$ & $0.66 \pm 0.01$ & $0.92 \pm 0.01$ & $1.25 \pm 0.01$ & $0.38 \pm 0.01$ & $0.45 \pm 0.01$ & $0.48 \pm 0.01$ & $0.68 \pm 0.01$ & $0.56 \pm 0.01$ \\
\hline Cy-3-cmglc & $0.65 \pm 0.01$ & $0.73 \pm 0.01$ & $0.78 \pm 0.01$ & $0.93 \pm 0.01$ & $0.25 \pm 0.00$ & $0.34 \pm 0.01$ & $0.32 \pm 0.01$ & $0.47 \pm 0.01$ & nd \\
\hline Pt-3-cmglc & $0.82 \pm 0.01$ & $0.75 \pm 0.01$ & $1.41 \pm 0.01$ & $1.58 \pm 0.01$ & $0.52 \pm 0.01$ & $0.64 \pm 0.01$ & $0.54 \pm 0.01$ & $0.80 \pm 0.01$ & $0.68 \pm 0.01$ \\
\hline Pn-3-cmglc & $1.62 \pm 0.01$ & $2.20 \pm 0.02$ & $2.40 \pm 0.02$ & $2.50 \pm 0.02$ & $1.01 \pm 0.01$ & $1.14 \pm 0.01$ & $1.04 \pm 0.01$ & $1.84 \pm 0.01$ & $1.30 \pm 0.01$ \\
\hline Mv-3-cmglc & $4.57 \pm 0.03$ & $6.80 \pm 0.05$ & $7.64 \pm 0.06$ & $8.41 \pm 0.07$ & $5.26 \pm 0.04$ & $6.72 \pm 0.05$ & $5.72 \pm 0.03$ & $6.78 \pm 0.05$ & $6.81 \pm 0.04$ \\
\hline Total anthocyanins ${ }^{*}$ & $16.1 \pm 0.2$ & $53.6 \pm 0.6 a$ & $508 \pm 6.2$ & $351 \pm 4.4$ & $96.1 \pm 1.1$ & $194 \pm 1.8 b$ & $47.6 \pm 0.5 a$ & $160 \pm 1.9$ & $194 \pm 2.3 b$ \\
\hline \multicolumn{10}{|l|}{ Vitisins } \\
\hline Vitisin-A & $69.0 \pm 0.58$ & $59.7 \pm 0.52$ & $39.5 \pm 0.36$ & $48.5 \pm 0.39$ & $45.3 \pm 0.42$ & $35.8 \pm 0.31$ & $56.5 \pm 0.47$ & $61.4 \pm 0.56$ & $46.5 \pm 0.43$ \\
\hline Ac-vitisin-A & $12.6 \pm 0.11$ & $16.4 \pm 0.14$ & $19.7 \pm 0.17$ & $25.2 \pm 0.20$ & $28.5 \pm 0.21$ & $31.5 \pm 0.29$ & $22.9 \pm 0.22$ & $20.4 \pm 0.19$ & $24.0 \pm 0.21$ \\
\hline$p$-Cm-vitisin-A & $11.7 \pm 0.10$ & $15.2 \pm 0.13$ & $12.4 \pm 0.11$ & $18.4 \pm 0.14$ & $11.6 \pm 0.10$ & $7.64 \pm 0.06$ & $11.3 \pm 0.10$ & $18.2 \pm 0.17$ & $11.0 \pm 0.10$ \\
\hline Vitisin-B & $6.67 \pm 0.05$ & $8.82 \pm 0.07$ & $28.4 \pm 0.24$ & $7.87 \pm 0.07$ & $7.08 \pm 0.06$ & $17.7 \pm 0.14$ & $9.39 \pm 0.08$ & nd & $10.4 \pm 0.09$ \\
\hline Ac-vitisin-B & nd & nd & nd & nd & $7.52 \pm 0.06$ & $7.33 \pm 0.06$ & nd & nd & $8.17 \pm 0.07$ \\
\hline Total vitisins $^{* *}$ & $6.94 \pm 0.06$ & $15.5 \pm 0.13 a$ & $53.1 \pm 0.57$ & $28.2 \pm 0.27$ & $14.1 \pm 0.12 \mathrm{a}$ & $34.9 \pm 0.30 c$ & $8.37 \pm 0.09$ & $46.1 \pm 0.38 b$ & $41.6 \pm 0.35 b$ \\
\hline \multicolumn{10}{|l|}{ Hydroxyphenyl-pyranoanthocyanins } \\
\hline 10-DHP-pymv-3-glc(pinotin A) & $45.3 \pm 0.40$ & $38.3 \pm 0.34$ & $25.2 \pm 0.23$ & $35.3 \pm 0.31$ & $21.5 \pm 0.18$ & $21.5 \pm 0.22$ & $24.4 \pm 0.21$ & $28.3 \pm 0.26$ & $29.3 \pm 0.30$ \\
\hline 10-DHP-pymv-3-acglc & nd & $10.4 \pm 0.11$ & nd & nd & $7.44 \pm 0.05$ & nd & nd & nd & nd \\
\hline 10-DHP-pymv-3-cmglc & nd & nd & nd & nd & $4.22 \pm 0.03$ & nd & nd & nd & nd \\
\hline 10-MHP-pymv-3-glc & $54.7 \pm 0.49$ & $38.0 \pm 0.36$ & $49.3 \pm 0.45$ & $43.3 \pm 0.39$ & $41.1 \pm 0.36$ & $42.6 \pm 0.45$ & $51.2 \pm 0.44$ & $42.7 \pm 0.43$ & $40.1 \pm 0.37$ \\
\hline 10-MHP-pymv-3-acglc & nd & $4.28 \pm 0.04$ & $11.8 \pm 0.11$ & $8.76 \pm 0.7$ & $18.6 \pm 0.18$ & $25.1 \pm 0.27$ & $15.4 \pm 0.13$ & $17.1 \pm 0.15$ & $19.1 \pm 0.15$ \\
\hline 10-MHP-pymv-3-cmglc & nd & $9.01 \pm 0.08$ & $13.8 \pm 0.11$ & $12.7 \pm 0.11$ & $7.09 \pm 0.08$ & $10.8 \pm 0.09$ & $9.02 \pm 0.08$ & $11.9 \pm 0.09$ & $11.5 \pm 0.09$ \\
\hline Total HP-pyranoanthocyanins ${ }^{* * *}$ & $1.09 \pm 0.02$ & $3.58 \pm 0.02$ & $7.35 \pm 0.06$ & $10.4 \pm 0.10$ & $5.44 \pm 0.04 a$ & $5.73 \pm 0.07 a, b$ & $2.35 \pm 0.02$ & $8.96 \pm 0.10$ & $6.28 \pm 0.06 b$ \\
\hline
\end{tabular}

mg/L, as malvidin 3-glucoside; nd, Dp, delphinidin; Cy, cyanidin; Pt, petunidin; Pn, peonidin; Mv, malvidin glc, 3-glucoside; acglc, 3-(6"-acetyl)-glucoside; cmglc, 3-(6" coumaroyl)-glucoside.

*** mg/L, as vitisin-A; Ac, 6"-acetyl derivative; Cm, 6"-coumaroyl derivative.

mg/L; HP-pyranoanthocyanins, hydroxyphenyl-pyranoanthocyanins. 10-MHP, 10-(4'"'-monohydroxyphenyl); 10-DHP, 10-(3'", $4^{\prime \prime \prime}$-dihydroxyphenyl).

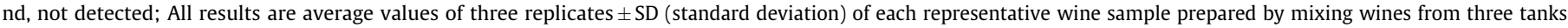
produced by same technological treatment

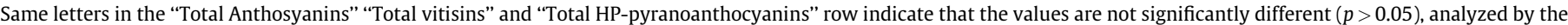
Tukey-Kramer Multiple Comparisons Test.

Abbreviations as in Table 1.

Limit of detection (LOD): Mv-glc $0.640 \mathrm{mg} / \mathrm{L}$.

The content of total flavonols found in Macedonian wines was in accordance to previously reported data for red wines (HermosínGutiérrez et al., 2011).

From the group of flavan-3-ols, (+)-catechin and (-)-epicatechin were the dominant compounds, present in range from 35.9 to $96.1 \mathrm{mg} / \mathrm{L}$ and 6.5 to $26.2 \mathrm{mg} / \mathrm{L}$, respectively. Catechin and epicatechin were present in highest concentration in Cabernet Sauvignon wines from 2006 and 2008, while Vranec wine from 2006 had lowest amount of both components. All wines contained higher content of procyanidin B2 compared to procyanidin B1.

Gallic acid was the only $p$-hydroxybenzoic acid quantified in the wines. The content of gallic acid was similar in all analyzed wines, regardless the variety and year of production.

With regard to the hydroxycinnamic acids derivatives, caftaric and coutaric acids were the dominant compounds in all analyzed wines. Caffeic acid was also present in all wines in lower levels than caftaric acid suggesting that hydrolysis of the ester occurred during storage (Table 4). And, from the stilbenes family, transresveratrol-3-glucoside was the dominant stilbene in all wines, followed by cis-resveratrol-3-glucoside, present from 27 to $57 \%$ and $19-38.9 \%$, respectively (on a molar basis) as presented in Table 5. Compared to few selected Brazilian wines (Lucena et al., 2010), Macedonian wines contained higher stilbene content.
The color properties of the wines from the three different years of production were analyzed by determination of the chromatic CIELAB characteristics (Table 5). Vranec wine from 2008 and Cabernet Sauvignon wine from 2006 exhibited the most intense color (lowest values for $L^{*}$ ), while no remarkable difference was observed for Cabernet Sauvignon and Merlot wines from the same year of production (2008). Because of aging, Vranec and Merlot produced in 2006 exhibited the lightest (highest values of $L^{*}$ ) and less pure red color (lowest values of $C^{*}$ ), with little purple hue (highest values of $h^{*}$ ). These results suggest that Vranec wine (produced in 2008) and Cabernet Sauvignon wine (from 2006) contained highest content not only of anthocyanins and pigments, but also of other phenolic compounds, such as flavonols, stilbenes and phenolic acids derivatives, which could contribute to wine color stabilization through participation in reactions of copigmentation forming stable color compounds, as it was observed in the wines (Tables 2-4). In fact, wine aging is accompanied by decrease of the content of anthocyanins and other phenolic compounds followed by color changes. Thus, the lowest amount of all analyzed classes of phenolics was observed in the Vranec wine produced in 2006. These results were expected, since the content of anthocyanins rapidly decreases during maturation and storage, mainly as a result of conversion of anthocyanins into other compounds, 
Table 3

Flavonol profiles of Vranec, Cabernet Sauvignon and Merlot wines (molar\% of each flavonol and total content of flavonols in $\mu$ mol/L).

\begin{tabular}{|c|c|c|c|c|c|c|c|c|c|}
\hline \multirow[t]{2}{*}{ Compounds/Wines } & \multicolumn{3}{|l|}{ Vranec } & \multicolumn{3}{|c|}{ Cabernet Sauvignon } & \multicolumn{3}{|l|}{ Merlot } \\
\hline & 2006 & 2007 & 2008 & 2006 & 2007 & 2008 & 2006 & 2007 & 2008 \\
\hline K-glcU & $2.25 \pm 0.02$ & $1.42 \pm 0.01$ & $1.21 \pm 0.01$ & $1.46 \pm 0.01$ & $0.93 \pm 0.01$ & $0.44 \pm 0.01$ & nd & $0.96 \pm 0.01$ & $1.33 \pm 0.01$ \\
\hline K-glc & $3.97 \pm 0.02$ & $3.12 \pm 0.03$ & $2.36 \pm 0.02$ & $2.34 \pm 0.02$ & $2.65 \pm 0.02$ & $2.48 \pm 0.02$ & $2.44 \pm 0.01$ & $2.25 \pm 0.01$ & $2.93 \pm 0.02$ \\
\hline $\mathrm{K}$ & $1.25 \pm 0.01$ & $1.28 \pm 0.01$ & $0.79 \pm 0.01$ & $1.29 \pm 0.01$ & $0.68 \pm 0.01$ & $0.28 \pm 0.00$ & $0.77 \pm 0.01$ & $1.16 \pm 0.01$ & $0.26 \pm 0.00$ \\
\hline Q-glcU & $31.6 \pm 0.32$ & $27.7 \pm 0.24$ & $24.8 \pm 0.24$ & $26.1 \pm 0.25$ & $23.9 \pm 0.21$ & $26.9 \pm 0.29$ & $24.0 \pm 0.21$ & $27.6 \pm 0.30$ & $32.6 \pm 0.31$ \\
\hline Q-glc & nd & $1.58 \pm 0.01$ & $5.50 \pm 0.05$ & $5.06 \pm 0.04$ & nd & nd & nd & nd & nd \\
\hline $\mathrm{Q}$ & $21.7 \pm 0.19$ & $18.7 \pm 0.16$ & $8.30 \pm 0.07$ & $19.6 \pm 0.21$ & $25.3 \pm 0.24$ & $9.40 \pm 0.09$ & $13.7 \pm 0.12$ & $28.2 \pm 0.30$ & $3.36 \pm 0.03$ \\
\hline I-glc & nd & $0.58 \pm 0.01$ & $1.18 \pm 0.01$ & $0.86 \pm 0.01$ & $0.31 \pm 0.01$ & $0.61 \pm 0.01$ & nd & $0.71 \pm 0.01$ & $0.68 \pm 0.01$ \\
\hline I & $3.94 \pm 0.3$ & $2.53 \pm 0.02$ & $1.10 \pm 0.01$ & $1.34 \pm 0.01$ & $6.28 \pm 0.06$ & $2.60 \pm 0.02$ & $1.93 \pm 0.01$ & $4.58 \pm 0.04$ & $0.84 \pm 0.01$ \\
\hline M-glcU & $3.01 \pm 0.2$ & $2.48 \pm 0.02$ & $2.25 \pm 0.02$ & $2.49 \pm 0.02$ & $2.86 \pm 0.02$ & $3.75 \pm 0.03$ & nd & $2.90 \pm 0.02$ & $3.56 \pm 0.03$ \\
\hline M-gal & nd & $0.17 \pm 0.00$ & $2.29 \pm 0.01$ & $0.48 \pm 0.01$ & $0.64 \pm 0.01$ & $0.74 \pm 0.01$ & nd & $0.66 \pm 0.01$ & $0.62 \pm 0.01$ \\
\hline M-glc & $6.90 \pm 0.5$ & $22.4 \pm 0.25$ & $34.3 \pm 0.31$ & $23.4 \pm 0.23$ & $6.57 \pm 0.06$ & $11.2 \pm 0.13$ & $4.28 \pm 0.02$ & $11.4 \pm 0.11$ & $13.3 \pm 0.12$ \\
\hline M & nd & $1.09 \pm 0.01$ & $0.86 \pm 0.01$ & $3.94 \pm 0.03$ & $3.23 \pm 0.03$ & $3.29 \pm 0.03$ & $7.86 \pm 0.06$ & $3.52 \pm 0.03$ & $3.04 \pm 0.02$ \\
\hline L-glc & $7.88 \pm 0.6$ & $7.23 \pm 0.07$ & $7.60 \pm 0.06$ & $6.01 \pm 0.06$ & $6.72 \pm 0.06$ & $9.16 \pm 0.09$ & $5.54 \pm 0.03$ & $5.60 \pm 0.05$ & $10.5 \pm 0.11$ \\
\hline $\mathrm{L}$ & $3.35 \pm 0.3$ & $1.34 \pm 0.01$ & $0.47 \pm 0.01$ & $0.80 \pm 0.01$ & $3.52 \pm 0.03$ & $3.67 \pm 0.03$ & $9.10 \pm 0.09$ & $2.24 \pm 0.02$ & $2.81 \pm 0.02$ \\
\hline S-glc & $12.6 \pm 0.13$ & $7.38 \pm 0.06$ & $6.40 \pm 0.06$ & $4.48 \pm 0.05$ & $15.2 \pm 0.13$ & $23.9 \pm 0.24$ & $28.2 \pm 0.27$ & $7.61 \pm 0.07$ & $23.2 \pm 0.22$ \\
\hline $\mathrm{S}$ & $1.64 \pm 0.01$ & $0.99 \pm 0.01$ & $0.59 \pm 0.01$ & $0.36 \pm 0.01$ & $1.21 \pm 0.01$ & $1.52 \pm 0.01$ & $2.14 \pm 0.01$ & $0.52 \pm 0.01$ & $0.88 \pm 0.01$ \\
\hline \multicolumn{10}{|l|}{ Total aglycon type flavonols } \\
\hline K-type & $7.47 \pm 0.07$ & $5.82 \pm 0.05$ & $4.37 \pm 0.04$ & $5.09 \pm 0.05$ & $4.26 \pm 0.04$ & $3.20 \pm 0.03$ & $3.21 \pm 0.02$ & $4.37 \pm 0.04$ & $4.51 \pm 0.04$ \\
\hline Q-type & $53.2 \pm 0.47$ & $48.0 \pm 0.51$ & 38. $6 \pm 0.39$ & $50.8 \pm 0.61$ & $49.2 \pm 0.46$ & $36.4 \pm 0.35$ & $37.7 \pm 0.35$ & $55.8 \pm 0.51$ & $35.9 \pm 0.33$ \\
\hline I-type & $3.94 \pm 0.03$ & $3.11 \pm 0.03$ & $2.28 \pm 0.02$ & $2.21 \pm 0.02$ & $6.59 \pm 0.06$ & $3.21 \pm 0.03$ & $1.93 \pm 0.02$ & $5.29 \pm 0.05$ & $1.52 \pm 0.01$ \\
\hline M-type & $9.91 \pm 0.09$ & $26.1 \pm 0.31$ & $39.7 \pm 0.41$ & $30.3 \pm 0.33$ & $13.3 \pm 0.15$ & $18.9 \pm 0.19$ & $12.1 \pm 0.12$ & $18.5 \pm 0.16$ & $20.6 \pm 0.22$ \\
\hline L-type & $11.2 \pm 0.12$ & $8.57 \pm 0.09$ & $8.07 \pm 0.09$ & $6.81 \pm 0.07$ & $10.2 \pm 0.09$ & $12.8 \pm 0.11$ & $14.6 \pm 0.15$ & $7.84 \pm 0.08$ & $13.4 \pm 0.15$ \\
\hline S-type & $14.2 \pm 0.13$ & $8.37 \pm 0.09$ & $6.99 \pm 0.08$ & $4.84 \pm 0.06$ & $16.4 \pm 0.15$ & $25.4 \pm 0.28$ & $30.3 \pm 0.27$ & $8.14 \pm 0.08$ & $24.1 \pm 0.28$ \\
\hline Total Flavonols $(\mu \mathrm{mol} / \mathrm{L})$ & $35.9 \pm 0.40$ & $88.5 \pm 0.91$ & $120 \pm 1.45 a$ & $152 \pm 1.46$ & $62.1 \pm 0.58$ & $45.5 \pm 0.39 b$ & $24.1 \pm 0.31$ & $119 \pm 1.23 a$ & $48.7 \pm 0.53 b$ \\
\hline
\end{tabular}

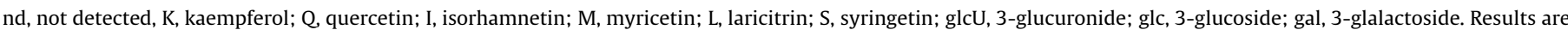

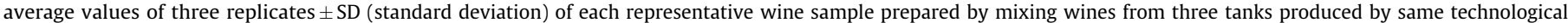
treatment.

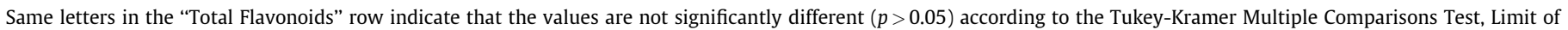
detection (LOD): Q-glc $0.125 \mathrm{mg} / \mathrm{L}, \mathrm{I}$-glc $-0.284 \mathrm{mg} / \mathrm{L}, \mathrm{M}-0.181 \mathrm{mg} / \mathrm{L}, \mathrm{K}-0.151 \mathrm{mg} / \mathrm{L}$.

such as new anthocyanin-derived pigments family, namely pyranoanthocyanins. But, during aging, not only the anthocyanins decreased, but also the pyranoanthocyanins and hydroxyphenylpyranoanthocyanins decreased, observing lowest amount in the wine from 2006, probably as a result of degradation or evolution of these pigments (Rentzsch et al., 2010).

The antioxidant activity of the commercial Macedonian wines from different varieties, determined by DPPH test ranged from

Table 4

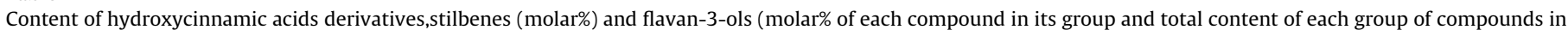
$\mathrm{mg} / \mathrm{L}$ ) and gallic acid (mg/L) in Vranec, Cabernet Sauvignon and Merlot wines.

\begin{tabular}{|c|c|c|c|c|c|c|c|c|c|}
\hline \multirow[t]{2}{*}{ Compounds/Wines } & \multicolumn{3}{|l|}{ Vranec } & \multicolumn{3}{|c|}{ Cabernet Sauvignon } & \multicolumn{3}{|l|}{ Merlot } \\
\hline & 2006 & 2007 & 2008 & 2006 & 2007 & 2008 & 2006 & 2007 & 2008 \\
\hline \multicolumn{10}{|c|}{ Hydroxycinnamic acid derivatives } \\
\hline trans-Caftaric acid & $53.0 \pm 0.48$ & $52.7 \pm 0.59$ & $59.3 \pm 0.49$ & $64.8 \pm 0.66$ & $10.2 \pm 0.09$ & $54.3 \pm 0.55$ & $55.4 \pm 0.48$ & $61.0 \pm 0.75$ & $59.3 \pm 0.55$ \\
\hline trans-Coutaric acid & $17.7 \pm 0.16$ & $19.0 \pm 0.21$ & $19.3 \pm 0.19$ & $16.4 \pm 0.16$ & $2.7 \pm 0.02$ & $14.8 \pm 0.16$ & $16.1 \pm 0.16$ & $16.7 \pm 0.18$ & $14.9 \pm 0.12$ \\
\hline cis-Coutaric acid & $2.7 \pm 0.02$ & $2.9 \pm 0.03$ & $3.2 \pm 0.03$ & $2.9 \pm 0.03$ & $1.2 \pm 0.01$ & $5.4 \pm 0.05$ & $4.3 \pm 0.04$ & $3.8 \pm 0.05$ & $5.3 \pm 0.05$ \\
\hline Caffeic acid & $7.5 \pm 0.08$ & $7.4 \pm 0.07$ & $5.4 \pm 0.05$ & $5.9 \pm 0.06$ & $58.9 \pm 0.53$ & $12.0 \pm 0.11$ & $12.9 \pm 0.11$ & $8.1 \pm 0.09$ & $9.7 \pm 0.09$ \\
\hline trans-Fertaric acid & $9.2 \pm 0.09$ & $9.8 \pm 0.11$ & $7.6 \pm 0.08$ & $5.2 \pm 0.05$ & $5.5 \pm 0.05$ & $8.2 \pm 0.09$ & $7.1 \pm 0.09$ & $7.9 \pm 0.08$ & $6.7 \pm 0.06$ \\
\hline p-Coumaric acid & $7.9 \pm 0.08$ & $5.9 \pm 0.06$ & $3.4 \pm 0.04$ & $0.5 \pm 0.01$ & $18.1 \pm 0.19$ & $1.8 \pm 0.01$ & $1.0 \pm 0.01$ & $0.5 \pm 0.01$ & $1.0 \pm 0.01$ \\
\hline Ethyl caffeoate & $0.8 \pm 0.01$ & $1.0 \pm 0.01$ & $1.2 \pm 0.01$ & $1.8 \pm 0.02$ & $1.2 \pm 0.01$ & $1.0 \pm 0.01$ & $1.7 \pm 0.01$ & $0.7 \pm 0.01$ & $1.5 \pm 0.01$ \\
\hline Ethyl coumarate & $1.1 \pm 0.01$ & $1.2 \pm 0.01$ & $0.7 \pm 0.01$ & $2.5 \pm 0.02$ & $2.1 \pm 0.02$ & $2.5 \pm 0.02$ & $1.6 \pm 0.01$ & $1.3 \pm 0.01$ & $1.5 \pm 0.01$ \\
\hline Total HCAD $(\mu \mathrm{mol} / \mathrm{L})$ & $275 \pm 3.23$ & $328 \pm 4.71$ & $352 \pm 4.00$ & $445 \pm 5.22$ & $228 \pm 2.99 \mathrm{a}, \mathrm{b}$ & $217 \pm 2.62 b$ & $240 \pm 3.01 a$ & $382 \pm 4.22$ & $248 \pm 3.29 a$ \\
\hline \multicolumn{10}{|l|}{ Stilbenes } \\
\hline trans-piceid & $48.5 \pm 0.49$ & $57.4 \pm 0.55$ & $27.1 \pm 0.29$ & $34.5 \pm 0.32$ & $38.6 \pm 0.36$ & $44.8 \pm 0.47$ & $38.5 \pm 0.35$ & $29.4 \pm 0.29$ & $40.2 \pm 0.41$ \\
\hline trans-resveratrol & $11.2 \pm 0.11$ & $12.5 \pm 0.14$ & $9.1 \pm 0.09$ & $21.2 \pm 0.22$ & $17.7 \pm 0.17$ & $18.0 \pm 0.19$ & $21.3 \pm 0.18$ & $14.5 \pm 0.13$ & $14.6 \pm 0.15$ \\
\hline cis-piceid & $29.4 \pm 0.33$ & $19.0 \pm 0.20$ & $26.4 \pm 0.29$ & $39.2 \pm 0.41$ & $35.1 \pm 0.36$ & $30.8 \pm 0.33$ & $31.9 \pm 0.28$ & $41.1 \pm 0.44$ & $38.9 \pm 0.39$ \\
\hline cis-resveratrol & $11.0 \pm 0.10$ & $11.1 \pm 0.11$ & $37.4 \pm 0.41$ & $5.1 \pm 0.05$ & $8.6 \pm 0.09$ & $6.3 \pm 0.07$ & $8.3 \pm 0.09$ & $15.0 \pm 0.17$ & $6.2 \pm 0.06$ \\
\hline Total stilbenes ( $\mu \mathrm{mol} / \mathrm{L})$ & $32.1 \pm 0.29$ & $26.9 \pm 0.28$ & $43.9 \pm 0.39 a$ & $39.0 \pm 0.36 b$ & $17.3 \pm 0.13$ & $14.0 \pm 0.11$ & $38.7 \pm 0.33 b$ & $46.2 \pm 0.39 a$ & $19.2 \pm 0.14$ \\
\hline \multicolumn{10}{|l|}{ Flavan-3-ols } \\
\hline Procyanidin B2 & $4.52 \pm 0.08 a$ & $5.04 \pm 0.05 a$ & $3.33 \pm 0.04 b$ & $4.83 \pm 0.07 a$ & $6.33 \pm 0.14$ & $3.48 \pm 0.07 b$ & $4.01 \pm 0.11$ & $5.11 \pm 0.13 a$ & $3.52 \pm 0.09 b$ \\
\hline Catechin & $96.1 \pm 3.78$ & $42.6 \pm 1.79$ & $68.2 \pm 2.44$ & $45.8 \pm 2.01 \mathrm{a}$ & $51.3 \pm 1.73 b$ & $47.6 \pm 2.13 a$ & $35.9 \pm 1.32 \mathrm{c}$ & $39.3 \pm 1.37 c$ & $51.4 \pm 1.78 b$ \\
\hline Procyanidin B1 & $12.3 \pm 0.66$ & $30.9 \pm 1.12$ & $23.0 \pm 0.99 a$ & $33.8 \pm 1.15 b$ & $33.8 \pm 1.10 \mathrm{~b}$ & $24.5 \pm 0.99 a$ & $23.4 \pm 1.04 a$ & $24.5 \pm 0.84 a$ & $20.8 \pm 2.11$ \\
\hline Total flavan-3-ols (mg/L) & $77.6 \pm 3.02$ & $87.5 \pm 2.98$ & $98.9 \pm 4.85$ & $150 \pm 6.01$ & $95.2 \pm 3.41$ & $122 \pm 4.3$ & $104 \pm 3.95$ & $111 \pm 3.9$ & $97.0 \pm 3.91$ \\
\hline Gallic acid (mg/L) & $11.1 \pm 0.48$ & $7.34 \pm 0.03 a$ & $7.64 \pm 0.02 a$ & $8.11 \pm 0.03 a$ & $8.98 \pm 0.35$ & $6.86 \pm 0.03$ & $7.83 \pm 0.29 a$ & $8.23 \pm 0.25 a$ & $7.63 \pm 0.26 a$ \\
\hline
\end{tabular}

HCAD, hydroxycinammic acid derivatives.

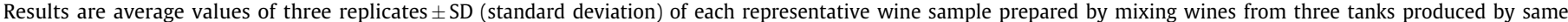

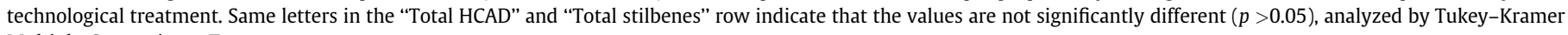
Multiple Comparisons Test. 
Table 5

Average value for CIELAB chromatic parameters, measured at pH 3.6 and antioxidant activity for Vranec, Cabernet Sauvignon and Merlot wines.

\begin{tabular}{|c|c|c|c|c|c|c|c|c|c|}
\hline \multirow[t]{2}{*}{ Color/Wines } & \multicolumn{3}{|l|}{ Vranec } & \multicolumn{3}{|c|}{ Cabernet Sauvignon } & \multicolumn{3}{|l|}{ Merlot } \\
\hline & 2006 & 2007 & 2008 & 2006 & 2007 & 2008 & 2006 & 2007 & 2008 \\
\hline$L^{*}$ & $52.2 \pm 0.25 b$ & $46.1 \pm 0.66$ & $29.6 \pm 0.21 a$ & $27.1 \pm 0.01 \mathrm{~s}$ & $50.8 \pm 0.15 b$ & $40.8 \pm 0.15$ & $69.3 \pm 0.15$ & $42.4 \pm 0.83 c$ & $41.8 \pm 0.24 c$ \\
\hline$C^{*}$ & $46.3 \pm 0.24 a$ & $51.5 \pm 0.38 b$ & $54.5 \pm 0.36 b$ & $57.8 \pm 0.24$ & $46.7 \pm 0.38 a$ & $53.4 \pm 0.03 b$ & $33.2 \pm 0.19$ & $52.4 \pm 0.35 b$ & $55.3 \pm 0.10 b$ \\
\hline$h^{*}$ & $19.6 \pm 0.25 a$ & $23.1 \pm 0.15$ & $13.5 \pm 0.26 b$ & $20.2 c \pm 0.25 a$ & $17.5 \pm 0.21$ & $13.5 \pm 0.18$ & $29.3 \pm 0.17$ & $20.7 \pm 0.06 a$ & $14.7 \pm 0.26 b$ \\
\hline AA & $11.6 \pm 0.55 a$ & $12.8 \pm 0.89 a$ & $12.5 \pm 0.71 \mathrm{a}$ & $11.1 \pm 0.26 a$ & $10.3 \pm 0.46 a$ & $11.2 \pm 0.46 a$ & $12.3 \pm 0.48 a$ & $13.0 \pm 0.38 a$ & $13.3 \pm 0.25 a$ \\
\hline
\end{tabular}

Same letters in the row indicate that the values are not significantly different $(p>0.05)$, analyzed by the Tukey-Kramer Multiple Comparisons Test.

$\mathrm{AA}$, Antioxidant activity, expressed $\mathrm{mmol} / \mathrm{L}$ as Trolox equivalents.

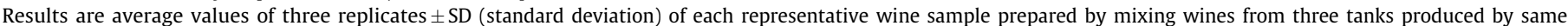
technological treatment.

Table 6

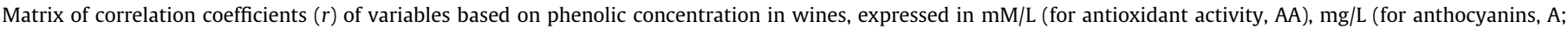

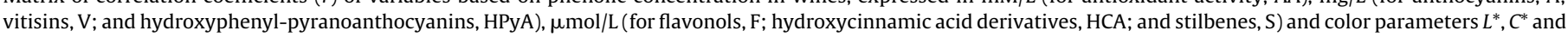
$h^{*}$.

\begin{tabular}{|c|c|c|c|c|c|c|c|c|c|c|}
\hline Variables & AA & A & V & HРyA & $\mathrm{F}$ & HCA & $S$ & $L^{*}$ & $C^{*}$ & $h^{*}$ \\
\hline AA & 1 & & & & & & & & & \\
\hline A & 0.046 & 1 & & & & & & & & \\
\hline V & 0.414 & 0.771 & 1 & & & & & & & \\
\hline HРyA & -0.002 & 0.719 & 0.727 & 1 & & & & & & \\
\hline $\mathrm{F}$ & 0.058 & 0.682 & 0.525 & 0.828 & 1 & & & & & \\
\hline HCA & 0.184 & 0.521 & 0.357 & 0.668 & 0.929 & 1 & & & & \\
\hline S & 0.372 & 0.348 & 0.236 & 0.285 & 0.552 & 0.720 & 1 & & & \\
\hline$L^{*}$ & 0.011 & -0.818 & -0.714 & -0.787 & -0.792 & -0.640 & -0.134 & 1 & & \\
\hline$C^{*}$ & 0.075 & 0.611 & 0.678 & 0.708 & 0.657 & 0.508 & -0.082 & -0.939 & 1 & \\
\hline$h^{*}$ & 0.137 & -0.554 & -0.639 & -0.371 & -0.155 & 0.092 & 0.390 & 0.674 & -0.720 & 1 \\
\hline
\end{tabular}

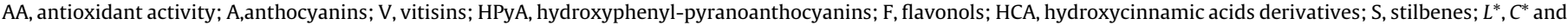
$h^{*}$, color parameters.

Values in bold are different from 0 with a significance level $\alpha=0.05$

10 to $18 \mathrm{mmol} / \mathrm{L}$ Trolox equivalents (Table 5). Cabernet Sauvignon wines presented lowest antioxidant activity $(10.9 \mathrm{mmol} / \mathrm{L} \mathrm{TE}$, on average) even, there was no significant difference $(p>0.05)$ observed between the values of all studied wines. The antioxidant activity of Vranec, Merlot and Cabernet Sauvignon were higher compared to those obtained by other authors for organic and conventional wines (Mulero et al., 2010) and similar to those obtained for red South African wines (De Beer et al., 2003).

These results give significant data for researchers, but also for the winemaking industry and consumers to understand the nature and content of phenolic compounds in different red wine varieties from Macedonian climate, as the most important components that influence the color, stability as well as sensorial properties of wines.

Factor analysis. Factor analysis was performed on the basis of the matrix of correlation coefficients using principal component factor analysis to identify and characterize the associations due to the phenolics content (Table 6). The concentration of every phenolic family, as well as antioxidant activity and color parameters were correlated to the concentration of the other phenolics separately and the values of the correlation coefficients are presented in the matrix. The matrix of dominant rotated factor loadings is shown in Table 7. Three factors were identified: Factor 1 formed the biggest association composed of the $L^{*}$ and $C^{*}$ color parameters and all analyzed phenolic groups, except the group of stilbenes which belong to the Factor 2 together with the hue value. Antioxidant activity belongs to Factor 3 . With respect to the principal component factor analysis, the first two components obtained explained $75.41 \%$ of the total variability of the original data: $54.9 \%$ was assigned to the first factor and $20.4 \%$ to the second factor. Fig. 4 shows the dispersion between the factors 1 and 2 and the loading for each variable. Three clusters of correlation can be observed. The first cluster contains anthocyanins (A), vitisins (V), hydroxyphenyl pyranoantocyanins (HPyA) and $C^{*}$ (red color), which means that $C^{*}$ values are correlated with the content of HPyA, A and V. The second cluster is formed by non-anthocyanin phenolics, including stilbenes (S), flavonols (F) and hydroxycinnamic acid derivatives (HCA). And, the third cluster contains the color parameters, $L^{*}$ and $h^{*}$. The first two clusters were located in the negative part of the factor 1 , together with the antioxidant activity and the second cluster was placed in the positive part of the factor 1 .

Dispersion of the scores of the principal component factor analysis associated with each wine and grouping of the wines is presented in Fig. 5. Projection of the wines on the first two principal component factors showed a clear separation of the samples according to the content of all phenolic families determined in wines. Thus, Vranec wine produced in 2008, Merlot produced in

Table 7

Matrix of dominant rotated factor loadings based on phenolic concentration in wines, expressed in $\mathrm{mM} / \mathrm{L}$ (for antioxidant activity, AA), $\mathrm{mg} / \mathrm{L}$ (for anthocyanins, $\mathrm{A}$; vitisins, V; and hydroxyphenyl-pyranoanthocyanins, HPyA), $\mu \mathrm{mol} / \mathrm{L}$ (for flavonols, F; hydroxycinnamic acid derivatives, HCA; and stilbenes, $S$ ) and color parameters $L^{*}$, $C^{*}$ and $h^{*}$.

\begin{tabular}{lccc}
\hline Variables & \multicolumn{1}{l}{$F$} & \multicolumn{1}{l}{$F 3$} \\
\hline AA & -0.133 & 0.262 & $\mathbf{0 . 5 5 1}$ \\
A & $-\mathbf{0 . 8 2 7}$ & -0.065 & 0.084 \\
V & $-\mathbf{0 . 8 1 1}$ & -0.192 & 0.552 \\
HPyA & $-\mathbf{0 . 8 5 7}$ & 0.035 & -0.096 \\
F & $-\mathbf{0 . 8 8 7}$ & 0.368 & -0.261 \\
HCA & $-\mathbf{0 . 7 4 9}$ & 0.606 & -0.208 \\
S & -0.354 & $\mathbf{0 . 8 0 6}$ & 0.219 \\
$L^{*}$ & $\mathbf{0 . 9 5 9}$ & 0.219 & 0.174 \\
$C^{*}$ & $-\mathbf{0 . 8 3 5}$ & -0.340 & -0.105 \\
$h^{*}$ & 0.537 & $\mathbf{0 . 7 8 4}$ & -0.069 \\
Variability (\%) & 54.9 & 20.4 & 8.44 \\
Cumulative \% & 54.9 & 75.4 & 83.8 \\
\hline
\end{tabular}

AA, antioxidant activity; A,anthocyanins; V, vitisins; HPyA, hydroxyphenylpyranoanthocyanins; F, flavonols; HCA, hydroxycinnamic acids derivatives; S, stilbenes; $L^{*}, C^{*}$ and $h^{*}$, color parameters.

Ivanova-Petropulos, Hermosín-Gutiérrez, Boros, Stefova, Stafilov, Vojnoski, Dörnyei, Kilár.

Values in bold correspond for each variable to the factor for which the squared cosine is the largest. 
Factor loadings (axes F1 and F2: $75.41 \%$ )

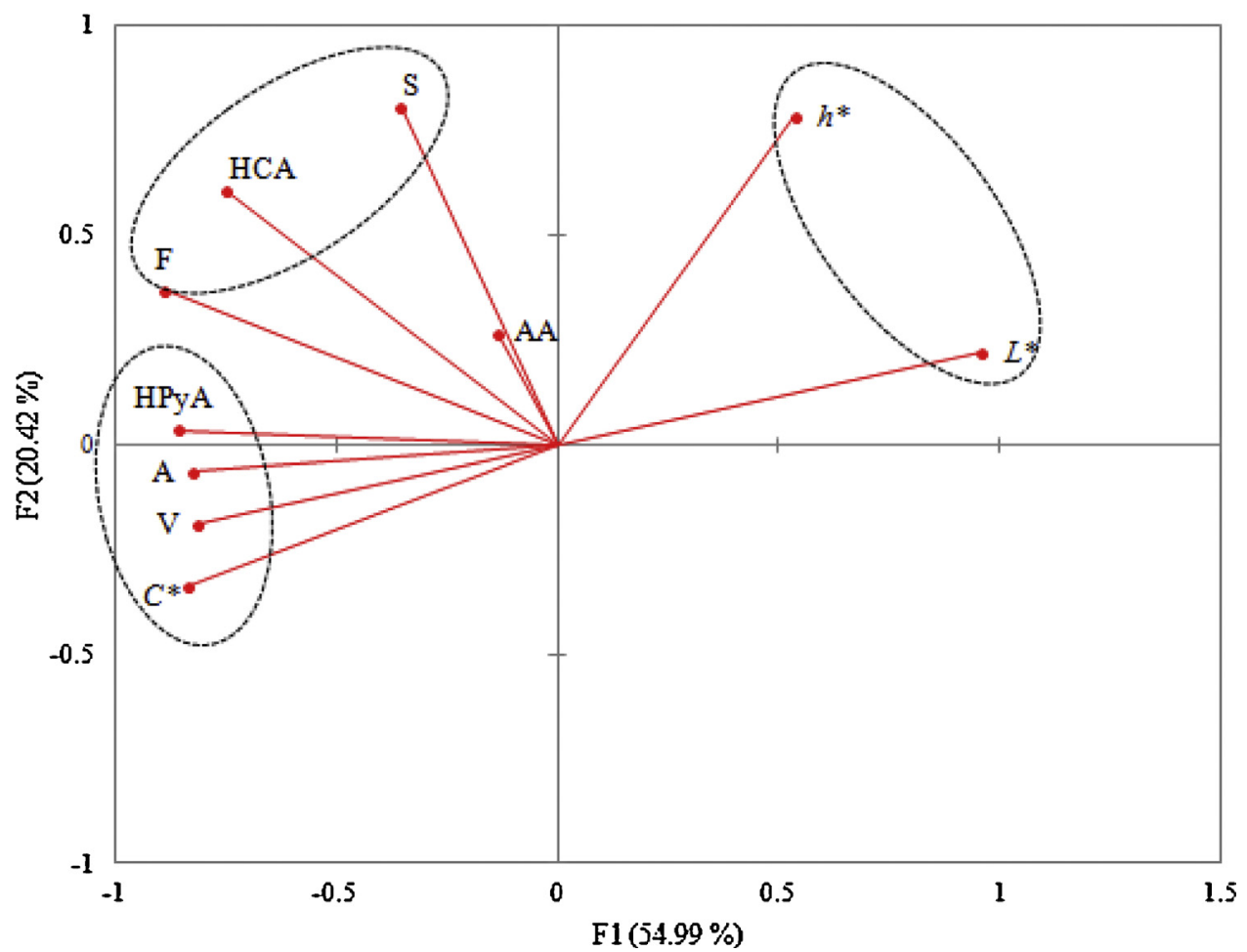

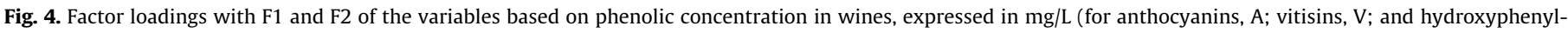
pyranoanthocyanins, HPyA), $\mu \mathrm{M} / \mathrm{L}$ (for flavonols, F; hydroxycinnamic acid derivatives, HCA; and stilbenes, S) and mM/L (for antioxidant activity, AA).

2007 and Cabernet Sauvignon produced in 2006, were richest in all phenolics compounds, and therefore, they were grouped and located in the negative part of the factor 1 . The other two groups were also associated according to the content of phenolic compounds, antioxidant activity and color characters. In addition, Vranec wines were clearly separated from the other wines, Merlot and Cabernet Sauvignon, located around the value 0 at the score plot.

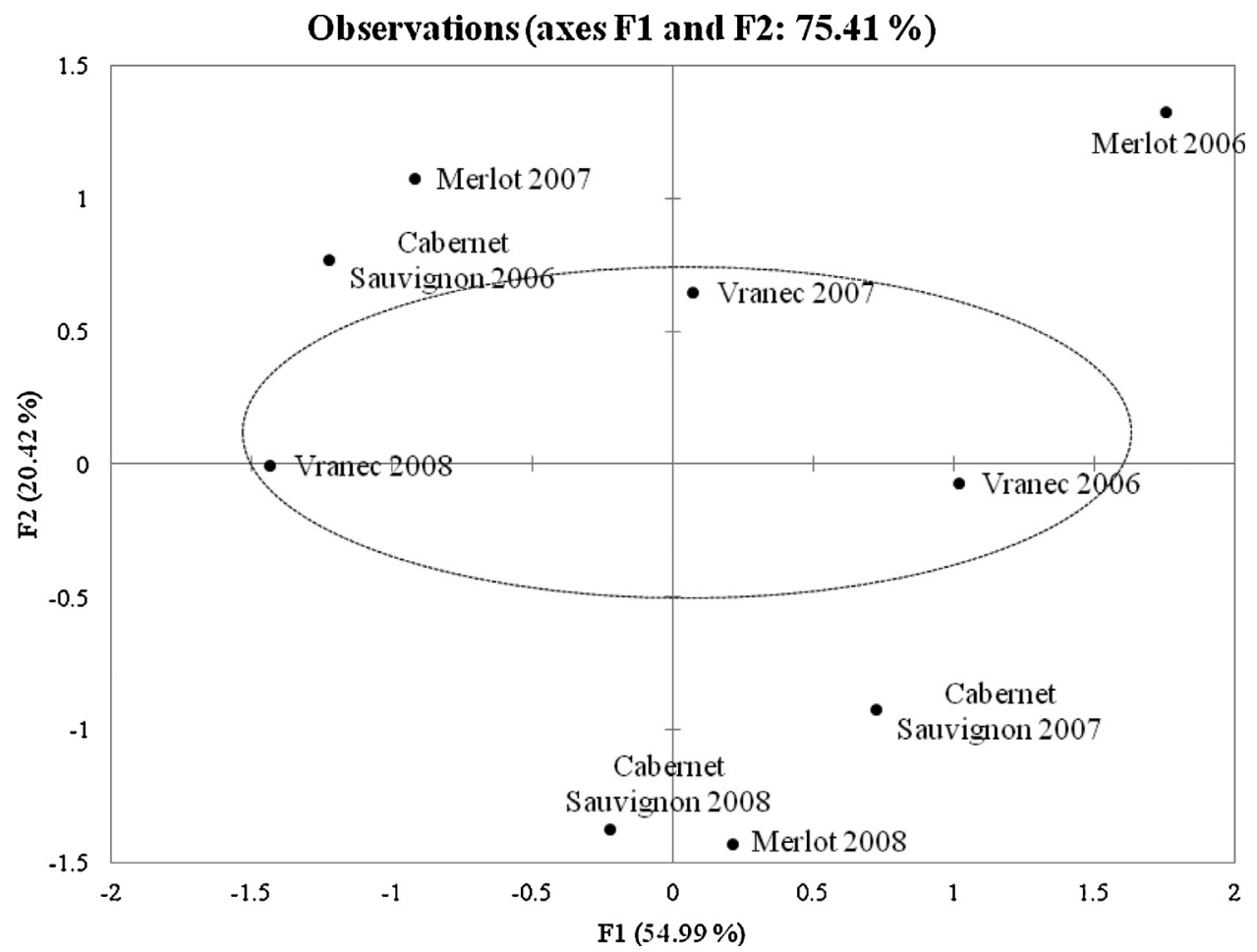

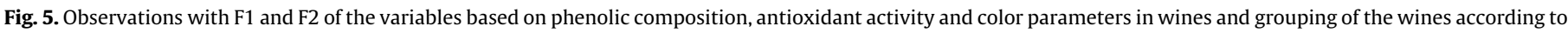
the content of the measured classes of phenolic compounds. 


\section{Conclusion}

Identification of phenolic compounds in Vranec, Merlot and Cabernet Sauvignon wines produced under Macedonian climate conditions was performed by HPLC-ESI-MS ${ }^{n}$ technique. In total, 65 phenolic compounds have been identified and quantified in the samples. In all analyzed wines, malvidin-3-glucoside and its 3-acetylglucoside and 3-p-coumaroylglucoside derivatives were the major compounds. Hydroxyphenyl-pyranoanthocyanins were for the first time identified and quantified in Macedonian wines. Regarding the wine age, Vranec wine produced in 2008 presented highest content of all phenolic families analyzed as well as most intensive color, followed by lower amounts in wines up to three years old. Cabernet Sauvignon and Merlot wines showed highest phenolics amount in 2006 and 2007, respectively, suggesting that the content of phenolics does not depend only on wine age, but also on the initial phenolic compounds levels, the conditions during storage, as well as the applied techniques for winemaking.

\section{Acknowledgements}

This work was financially supported by the CEEPUS Program realized through the CEEPUS network (CIII-HU-0010-06 - Teaching and Learning Bioanalysis) covering the study stay of Violeta Ivanova-Petropulos at the University of Pecs, Hungary. Á.D. acknowledges the support of the János Bolyai Research Scholarship (Hungarian Academy of Sciences). Authors express gratitude to $\mathrm{Mr}$. Kire Trajkov from Tikveš Winery, Kavadarci, Republic of Macedonia for providing the wine samples and data for the meteorological and viticultural conditions.

\section{References}

Alcalde-Eon, C., Escribano-Bailón, M.T., Santos-Buelga, C., Rivas-Gonzalo, J.C., 2006 Changes in the detailed pigment composition of red wine during maturity and ageing. A comprehensive study. Analytica Chimica Acta 563, 238-254.

Ayala, F., Echávarri, J.F., Negueruela, A.I., 1997. A new simplified method for measuring the color of wines. I. Red and rose wines. American Journal of Enology and Viticulture 48, 357-363.

Bakker, J., Timberlake, C.F., 1997. Isolation, identification and characterization of new color-stable anthocyanins occurring in some red wines. Journal of Agricultural and Food Chemistry 45, 35-43.

Bautista-Ortín, A.B., Fernández-Fernández, J.I., López-Roca, J.M., Gómez-Plaza, E., 2007. The effects of enological practices in anthocyanins, phenolic compounds and wine colour and their dependence on grape characteristics. Journal of Food Composition and Analysis 20, 546-552.

Blanco-Vega, D., López-Bellido, F.J., Alía-Robledo, J.M., Hermosín-Gutiérrez, I. 2011. HPLC-DAD-ESI-MS/MS characterization of pyranoanthocyanins pigments formed in model wine. Journal of Agricultural and Food Chemistry 59, 9523-9531.

Brand-Williams, W., Cuvelier, M.E., Berset, C., 1995. Use of a free radical method to evaluate antioxidant activity. LWT-Food Science and Technology 28, 25-30.

Burns, J., Gardner, P.T., O’Neil, J., Crawford, S., Morecroft, I., Mc Phail, D.B., Lister, C., Matthews, D., MacLean, M.R., Lean, M.E.J., Crozier, A., 2000. Relationship among antioxidant activity, vasodilation capacity, and phenolic content of red wines. Journal of Agricultural and Food Chemistry 48, 220-230.

Carpentieri, A., Marino, G., Amoresano, A., 2007. Rapid fingerprinting of red wines by MALDI mass spectrometry. Analytical and Bioanalytical Chemistry 389 (3), 969-982.

Castillo-Muñoz, N., Gómez-Alonso, S., García-Romero, E., Gómez, M.V., Velders, A.H. Hermosín-Gutiérrez, I., 2009. Flavonol 3-O-glycosides series of Vitis vinifera cv. Petit Verdot red wine grapes. Journal of Agricultural and Food Chemistry 57, 209-219.

Castillo-Muñoz, N., Gómez-Alonso, S., García-Romero, E., Hermosín-Gutiérrez, I. 2007. Flavonol profiles of vitis vinifera red grapes and their single-cultivar wines. Journal of Agricultural and Food Chemistry 55, 992-1002.

Chinnici, F., Sonni, F., Natali, N., Galassi, S., Riponi, C., 2009. Colour features and pigment composition of Italian carbonic macerated red wines. Food Chemistry $113,651-657$

Cren-Olive, C., 2000. Characterization of methylation site of monomethylflavan-3ols by liquid chromatography/electrospray ionisation tandem mass spectrometry. Rapid Communications in Mass Spectrometry 14, 2312-2319.

De Beer, D., Joubert, E., Gelderblom, W.C.A., Manley, M., 2003. Antioxidant activity of South African red and white cultivar wines: free radical scavenging. Journal of Agricultural and Food Chemistry 51, 902-909.
De Villers, A., Vanhoenacker, G., Majek, P., Sandra, P., 2004. Determination of anthocyanins in wine by direct injection liquid chromatography-diode array detection-mass spectrometry and classification of wines using discriminant analysis. Journal of Chromatography A 1054, 195-204.

Downey, M.O., Harvey, J.S., Robinoson, S.P., 2003. Analysis of tannins in seeds and skins of Shiraz grapes. Australian Journal of Grape and Wine Research 9, 15-27.

Ferrari, E., Foca, G., Vignali, M., Tassi, L., Ulrici, A., 2011. Adulteration of the anthocyanin content of red wines: perspectives for authentication by Fourier transform-near infrared and ${ }^{1} \mathrm{H}$ NMR spectroscopies. Analytica Chimica Acta 701, 139-151

Fulcrand, H., Cameira dos Santos, P.J., Sarni-Manchado, P., Cheynier, V., FavreBonvin, J., 1996. Structure of new anthocyanin-derived wine pigments. Journal of Chemical Society Perkin Transactions 1 7, 735-739.

Gil-Muñoz, R., Moreno-Pérez, A., Vila-López, R., Fernández-Fernández, J.I., MartínezCutillas, A., Gómez-Plaza, E., 2009. Influence of low temperature prefermentative techniques on chromatic and phenolic characteristics of Syrah and Cabernet Sauvignon wines. European Food Research and Technology 228, 777-788.

Gomez-Alonso, S., Garcia-Romero, E., Hermosin-Gutiérrez, I., 2007. HPLC analysis of diverse grape and wine phenolics using direct injection and multidetection by DAD and fluorescence. Journal of Food Composition and Analysis 20, 618-626.

He, J., Santos-Buelga, C., Mateus, N., De Freitas, V., 2006. Isolation and quantification of oligomeric pyranoanthocyanin-flavanol pigments from red wines by combination of column chromatography techniques. Journal of Chromatography A $1134,215-225$.

Hermosín-Gutiérrez, I., Castillo-Muñoz, N., Gómez-Alonso, S., García-Romero, E., 2011. Chapter 8: Flavonol Profiles for Grape and Wine Authentication. In: Ebeler, S.E., Takeoka, G.R., Winterhalter, P. (Eds.), Progress in Authentication of Food Wine, ACS Symposium Series. American Chemical Society, Washington, DC, pp. 113-129.

Ivanova, V., Dörnyei, Á., Márk, L., Vojnoski, B., Stafilov, T., Stefova, M., Kilár, F., 2011a. Polyphenolic content of Vranec wines produced by different vinification conditions. Food Chemistry 124 (1), 316-325

Ivanova, V., Dörnyei, Á., Stefova, M., Stafilov, T., Vojnoski, B., Kilár, B., Márk, L., 2011b. Rapid MALDI-TOF-MS detection of anthocyanins in wine and grape using different matrices. Food Analytical Methods 4, 108-115.

Ivanova, V., Stefova, M., Vojnoski, B., Dörnyei, Á., Márk, L., Dimovska, V., Stafilov, T., Kilár, F., 2011c. Identification of polyphenolic compounds in red and white grape varieties grown in $\mathrm{R}$. Macedonia and changes of their content during ripening. Food Research International 44, 2851-2869.

Ivanova, V., Stefova, M., Vojnoski, B., 2009. Assay of phenolic profile of Merlot wines from Macedonia: effect of maceration time, storage, $\mathrm{SO}_{2}$ and temperature of storage. Macedonian Journal of Chemistry and Chemical Engineering 28, 141-149.

Ivanova, V., Vojnoski, B., Stefova, M., 2011e. Effect of the winemaking practices and aging on phenolic content of smederevka and chardonnay wines. Food and Bioprocess Technology 4, 1512-1518.

Jemal, M., Ouyang, Z., Teitz, D.S., 1998. High performance liquid chromatography mobile phase composition optimization for the quantitative determination of a carboxylic acid compound in human plasma by negative ion electrospray high performance liquid chromatography tandem mass spectrometry. Rapid Communications in Mass Spectrometry 12, 429-434.

Jurd, L., 1967. Anthocyanins and related compounds XI. Catechin flavylium salt condensation reaction. Tetrahedron 23, 1057-1064

Kelebek, H., Canbas, A., Selli, S., 2007. HPLC-DAD-MS analysis of anthocyanins in rose wine made from cv. Öküzgöözü grapes, and effect of maceration time on anthocyanin content. Chromatographia 66, 207-212.

Kostadinović, S., Wilkens, A., Stefova, M., Ivanova, V., Vojnoski, B., Mirhosseini, H., Winterhalter, P., 2012. Stilbene levels and antioxidant activity of Vranec and Merlot wines from Macedonia: effect of variety and enological practices. Food Chemistry 135, 3003-3009.

Koyama, K., Goto-Yamamoto, N., Hashizme, K., 2007. Influence of maceration temperature in red wine vinification on extraction of phenolics from berry skins and seeds of grape (Vitis vinifera). Bioscience, Biotechnology, and Biochemistry 71, 958-965.

Langcake, P., 1981. Disease resistance of Vitis spp. and the production of the stress metabolites resveratrol, $\varepsilon$-viniferin, $\alpha$-viniferin and pterostilbene. Physiology and Plant Pathology 18, 213-226.

Langcake, P., Pryce, R.J., 1976. The production of resveratrol by Vitis vinifera and other members of the Vitacee as a response to infection or injury. Physiology and Plant Pathology 9, 77-86.

Lucena, A.P.S., Nascimento, R.J.B., Maciel, J.A.C., Tavares, J.X., Barbosa-Filho, J.M., Oliveira, E.J., 2010. Antioxidant activity and phenolics content of selected Brazilian wines. Journal of Food Composition and Analysis 23, 30-36.

Mateus, N., Carvalho, E., Carvalho, A.R.F., Melo, A., Gonzlez-Params, A.M., Santos-Buelga, C., Silva, A.M.S., de Freitas, V., 2003. Isolation and structural characterization of new acylated anthocyanin-vinyl-flavanol pigments occurring in aging red wines. Journal of Agricultural and Food Chemistry 51 (1), 277-282

Mateus, N., Silva, A.M., Santos-Buelga, C., Rivas-Gonzalo, J.C., De Freitas, V., 2002. Identificaton of anthocyanin-flavanol pigments in red wines by NMR and mass spectrometry. Journal of Agricultural and Food Chemistry 50, 2110-2116.

Mateus, N., Oliveira, J., Santos-Buelga, C., Silva, A.M., De Freitas, V., 2004. NMR structure characterization of a new vinylpyranoanthocyanincatechin pigment (a portisin). Tetrahedron Letters 45, 3455-3457.

Montealegre, R.R., Peces, R.R., Vozmediano, J.L.C., Gascueña, J.M., Romero, E.G., 2006. Phenolic compounds in skin and seeds in ten grape Vitis vinifera varieties grown in a warm climate. Journal of Food Composition and Analysis 19, 687-693. 
Mulero, J., Pardo, F., Zafrilla, P., 2010. Antioxidant activity and phenolic composition of organic and conventional grapes and wines. Journal of Food Composition and Analysis 23, 569-574.

Oliveira, J., Azevedo, J., Silva, A.M.S., Teixeira, N., Cruz, L., Mateus, N., de Freitas, V., 2010. Pyranoanthocyanin dimers: a new family of turquoise blue anthocyaninderived pigments found in port wine. Journal of Agricultural and Food Chemistry 58, 5154-5159.

Pace-Asciak, C.R., Hahn, S., Diamandis, E.P., Soleas, G., Goldberg, D.M., 1995. The red wine phenolics trans-resveratrol and quercetin block human platelet aggregation and eicosanoid synthesis: implications for protection against coronary heart disease. Clinica Chimica Acta 235, 207-219.

Reed, J.D., Krueger, C.G., Vestling, M.M., 2005. MALDI-TOF mass spectrometry of oligomeric food polyphenols. Phytochemistry 66 (18), 2248-2263.

Remy, S., Fulcrand, H., Labarbe, B., Cheynier, V., Moutounet, M., 2000. First confirmation in red wine of products resulting from direct anthocyanin-tannin reactions. Journal of the Science of Food and Agriculture 80, 745-751.

Rentzsch, M., Schwarz, M., Winterhalter, P., Blanco-Vega, D., Hermosín-Gutiérrez, I., 2010. Survey on the content of vitisin A and hydroxyphenyl-pyranoanthocyanins in Tempranillo wines. Food Chemistry 119, 1426-1434.

Rentzsch, M., Schwarz, M., Winterhalter, P., Hermosin-Gutiérrez, I., 2007. Formation of hydroxyphenyl-pyranoanthocyanins in Grenache wines: precursor levels and evolution during aging. Journal of Agricultural and Food Chemistry 55, 4883-4888.

Rivero-Perez, M.D., Muniz, P., Gonzalez-Sanjose, M.L., 2008. Contribution of anthocyanin fraction to the antioxidant properties of wine. Food and Chemical Toxicology 46, 2815-2822.

Rubilar, M., Pinelo, M., Shene, C., Sineiro, J., José Nuñez, M., 2007. Separation and HPLC-MS identification of phenolic antioxidants from agricultural residues: almond hulls and grape pomace. Journal of Agricultural and Food Chemistry 55, 10101-10109.

Sarni-Manchado, P., Cheynier, V., Moutounet, M., 1999. Interactions of grape seed tannins with salivary proteins. Journal of Agricultural and Food Chemistry 47, 42-47.
Schwarz, M., Hofmann, G., Winterhalter, P., 2004. Investigations on anthocyanins in wines from Vitis vinifera cV. Pinotage: factors influencing the formation of pinotin A and its correlation with wine age. Journal of Agricultural and Food Chemistry 52, 498-504.

Somers, T.C., 1966. Wine tannins isolation of condensed flavanoid pigments by gelfiltration. Nature 209, 368-370.

Somers, T.C., 1971. The polymeric nature of wine pigments. Phytochemistry 10 2175-2186.

Spáčil, Z., Shariatgorji, M., Amini, N., Solich, P., Ilag, L.L., 2009. Matrix-less laser desorption/ionisation mass spectrometry of polyphenols in red wine. Rapid Communications in Mass Spectrometry 23, 1834-1840.

Stefova, M., Ivanova, V., 2011d. Fruits \& Cereal Bioactives, Sources, Chemistry, and Applications. Chapter 20: Analytical Methodology for Characterization of Grape and Wine Phenolic Bioactives CRC Press, Taylor \& Francis, , pp. 409-427.

Timberlake, C.F., Bridle, P., 1976. Interactions between anthocyanins, phenolic compounds, and acetaldehyde and their significance in red wines. American Journal of Enology and Viticulture 27 (3), 97-105.

Wang, H., Race, E.J., Shrikhande, A.J., 2003. Anthocyanin transformation in Cabernet Sauvignon wine during aging. Journal of Agricultural and Food Chemistry 51, 7989-7994.

Wang, J., Sporns, P., 1999. Analysis of anthocyanins in red wine and fruit juice using MALDI-MS. Journal of Agricultural and Food Chemistry 47 (5), 2009-2015.

Wu, X., Prior, R.L., 2005. Identification and characterization of anthocyanins by high-performance liquid chromatography-electrospray ionization-tandem mass spectrometry in common foods in the United States: vegetables, nuts, and grains. Journal of Agricultural and Food Chemistry 53, 3101-3113.

Wulf, L.W., Nagel, C.W., 1978. High-pressure liquid-chromatographic separation of anthocyanins of Vitis vinifera. American Journal of Enology and Viticulture 29, 42-49.

Zhang, Y., Vareed, S.K., Nair, M.G., 2005. Human tumor cell growth inhibition by non-toxic anthocyanidins, the pigments in fruits and vegetables. Life Sciences 76, 1465-1472. 